\title{
Optimal Choice of Monetary Instruments in an Economy with Real and Liquidity Shocks*
}

\author{
Joydeep Bhattacharya ${ }^{\dagger} \quad$ Rajesh Singh \\ Iowa State University
}

\begin{abstract}
Faced with real and nominal shocks, what should a benevolent central bank do, fix the money growth rate or target the inflation rate? In this paper, we make a first attempt at studying the optimal choice of monetary policy instruments in a micro-founded model of money. Specifically, we produce an overlapping generations economy in which limited communication and stochastic relocation creates an endogenous transactions role for fiat money. We find that when the shocks are real, welfare is higher under money growth targeting; when the shocks are nominal and not large, welfare is higher under inflation rate targeting. While under inflation rate targeting, it is always optimal to pursue an expansionary policy, it is never optimal to do so under money growth targeting.
\end{abstract}

JEL Classification: E31, E42, E63

Keywords: overlapping generations, random relocation model, monetary targeting, interest rate targeting

*This revised version: May 3, 2007. We thank the editor Peter Ireland and two anonymous referees for their invaluable input, and David Mills and participants at the 2006 Winter Meetings of the Econometric Society and the Midwest Macroeconomics Meetings in Iowa City for many helpful comments.

${ }^{\dagger}$ Correspondence: Joydeep Bhattacharya, Department of Economics, Iowa State University, Ames IA 50011, USA; e-mail: joydeep@iastate.edu 


\section{Introduction}

How should a monetary authority decide whether to use the money stock or the interest rate as its policy instrument of choice? Using a stochastic IS-LM model, with reduction in variability of aggregate output as the yardstick, Poole (1970) was the first to pose this "instrument problem". His advice was clear and precise: when the shocks are real in nature, fix the money supply; if the shocks are monetary, fix the interest rate. This prescription continues to guide monetary authorities around the globe even today and remains to date among the most influential policy counsels in monetary economics.

Surprisingly, though, Poole's instrument problem has received almost no attention in formal micro-founded models of money, a lacuna we attempt to remedy in this paper. ${ }^{1}$ To that end, we produce a two-period lived pure-exchange overlapping generations model in the tradition of Townsend (1987) and Champ, Smith, and Williamson (1997) where limited communication and stochastic relocation create an endogenous transactions role for fiat money. ${ }^{2}$ At the end of each period a fraction (deterministic or random) of agents is relocated (the "movers") to a location different from the one they were born in and the only asset they can use to "communicate" with their past is fiat money. This allows money to be held even when dominated in rate of return. The other asset is a commonly available linear storage technology with a fixed real return. The "stochastic relocations" act like shocks to agents' portfolio preferences and, in particular, trigger liquidations of some assets at potential losses. They have the same consequences as "liquidity preference shocks" in Diamond and Dybvig (1983), and motivate a role for banks that take deposits, hold cash reserves, and make other less liquid investments. Depending on agents' risk aversion, the banks' cash reserves are sensitive/insensitive to the real return on money.

We study two variants of this model, one in which there are real shocks (the

\footnotetext{
${ }^{1}$ Stern and Miller (2004) argue that questions regarding optimal monetary policy are best conducted in dynamic, stochastic general equilibrium models of money that incorporate a rationale for why money is held even when dominated in return by assets of similar risk profile. Poole (1970) satisfies all these desiderata except for the return dominance issue and the fact that his criterion for optimality is not agents' welfare. It also deserves mention that our work is not directly comparable to that of Poole's because monetary disturbances have no direct effect on output variability in our setup.

${ }^{2}$ The random relocation with limited communication model was popularized by Champ, Smith, and Williamson (1997) and has been used to investigate monetary policy issues in Paal and Smith (2000), Smith (2002), Antinolfi, Huybens, and Keister (2001), among others.
} 
young-age good endowment of the agents is stochastic), and one where the fraction of agents relocating is itself random (liquidity preference or monetary shocks). In either case, banks can promise a real return to only the non-movers. For the movers, the banks can promise an amount of money (paid out of the bank's reserve holdings) but not the real return on it. To see this, consider the case of endowment shocks. Here, the bank this period cares about next period's endowment because the latter will potentially influence that period's money demand and hence the price level and therefore affect the return on money between this period and the next. But next period's money demand depends on the following period's endowment, and so on. We assume that all agents know the distributions of the real or monetary shocks and form expectations about the return on money conditional on these distributions. We focus solely on long run stationary equilibria under which agents expectations are coordinated across time, i.e., expectations of one generation are validated by the behavior of the next and so on ad infinitum.

Can the model tell us if inflation targeting (or interest rate targeting) is superior in an ex ante welfare sense to money growth targeting, and when? As a benchmark, we start by studying the deterministic case. Here, as originally noted by Poole, "it obviously makes no difference whatsoever whether the policy prescription is in terms of setting the interest rate or in terms of setting the money stock...". The best policy, as discussed in Bhattacharya, Haslag, and Russell (2005) is to hold the money stock fixed (zero inflation). Here the social opportunity cost of using money is the lost return from storage while the private opportunity cost of money is the nominal interest rate; these are equalized when the net inflation rate is zero. In the deterministic case, since every period is exactly the same, the government faces a static problem and hence cares only about this intratemporal margin. With shocks, however, the government's problem is generically no longer static; an intertemporal (intergenerational) margin appears. Since shocks hit different generations asymmetrically, the government has to pay attention to providing some amount of intergenerational insurance. To achieve this, the government may opt to trade off intratemporal for intertemporal efficiency and this may cause optimal monetary policy to deviate from the zero inflation policy.

When shocks are introduced, we are able to make a fair bit of analytical progress under the assumption of logarithmic (henceforth "log") utility. When the economy 
is hit with i.i.d. shocks to the endowment drawn from a general distribution, we can show that the ex ante welfare maximizing (henceforth "optimal") net money growth rate is zero (fixed money supply). The corresponding optimal inflation targeting policy calls for positive inflation. We are also able to show that an optimally chosen fixed money growth rate is welfare superior to an optimally chosen fixed inflation rate. For the class of CRRA utility functions with coefficient of relative risk aversion $\phi$, computations reveal that the optimal net money growth rate is negative for $\phi<1$, zero for $\phi=1$, and negative again for $\phi>1$. For the entire range of $\phi$ studied, the corresponding optimal inflation targeting policy calls for positive inflation and optimal monetary targeting is welfare superior to optimal inflation targeting.

For the most part, the situation is exactly reversed when the shocks are monetary in nature, that is they affect the fraction of agents relocating. For logarithmic utility, we can prove that optimal monetary targeting involves a negative net money growth rate while the corresponding optimal inflation targeting policy calls for positive inflation. For "small enough" liquidity shocks, we can also prove that inflation targeting does a better job than monetary targeting; this result is however reversed for "large" shocks. Numerical experiments confirm that the flavor of these results carries over to the CRRA case for a wide range of $\phi$.

Overall, two strong themes emerge. First, our results indicate that when the shocks are real, welfare is higher under money growth targeting; when the shocks are nominal and not large, welfare is higher under inflation targeting. Secondly, while under inflation targeting it is always optimal to pursue an expansionary policy, it is never optimal to do so under money growth targeting.

Almost all the work done in this area employs models with sticky or staggered prices, and very few, use welfare criteria to answer Poole's original question. Prominent examples of work in the rigid prices tradition are surveyed in Woodford (2003). Using a deterministic overlapping generations model, Smith (1994) compares the two targeting procedures in terms of their efficiency properties and goes on to isolate a "tension between efficiency and determinacy" of monetary equilibria reminiscent of the nineteenth century quantity theory versus real bills doctrine controversy. This tension is not a focus of our analysis. Liquidity shocks in the random relocation environment (and their relation to banking crises) have also been studied in Champ, 
Smith, and Williamson (1997), Paal and Smith (2000), Smith (2002) and Antinolfi, Huybens, and Keister (2001), and Antinolfi and Keister (2006). Our treatment of liquidity shocks is different from that in these papers (see footnote 9 on this).

In a closely related paper, Porqueras and Smith (2003) study the optimal level of interest rate smoothing under seasonal fluctuations. They consider deterministic two-period cycles of endowments, relocation, and storage returns and characterize the properties of periodic equilibria under monetary and interest rate targeting. By computing periodic interest rate policies that maximize welfare, they show that liquidity shocks require relatively higher interest rate smoothing than endowment shocks. Our paper substantially enlarges the scope of the analysis undertaken by Gomis-Porqueras and Smith (2003). Not only do we evaluate the best rule for each monetary policy instrument, we also rank monetary targeting against interest rate targeting for each type of shock, an exercise closer in spirit to Poole (1970). It is also worth reiterating that, while our results hold for the whole class of CRRA preferences, all of our results for logarithmic preferences are derived analytically, allowing us to clearly lay out the economic intuition that underlie these results. More importantly, by undertaking a dynamic rational expectations equilibrium approach, our paper makes a theoretical advance; it enables a tractable analysis of price-level uncertainty within a stationary setting and within the context of the aforementioned literature on stochastic relocation models, a feature not present in the earlier papers.

The plan for the rest of the paper is as follows. In the next section, we outline the baseline model without uncertainty and compute optimal monetary policies. In Section 3, we study the role of endowment uncertainty in shaping the optimal choice of monetary instruments. In Section 4, we do the same with money demand shocks. Section 5 presents the results from the computational experiments under CRRA utility. In Section 6.1 we revert to logarithmic preferences for studying state-contingent rules and then contrast them with the optimal money growth and inflation rules. In that section, we also discuss the welfare implications of monetary injections that are implemented through proportional transfers. Section 7 concludes. Proofs of all major results are in the appendices. 


\section{The Environment}

\subsection{Primitives}

We consider an economy consisting of an infinite sequence of two period lived overlapping generations. Time $t$ is discrete and runs from $\{t\}_{0}^{\infty}$. At each date $t$, a unit mass of identical young agents is symmetrically assigned to one of two locations. There is a single good that may be consumed or stored. Each two-period-lived agent is endowed with $w_{t}>0$ units of this good at date $t$ when young and nothing when old; in Section 3 below we study a setting in which $w$ is stochastic where we assume $w$ is revealed at the start of any date.

Let $c_{2, t+1}$ denote the consumption of the final good by a representative old agent born at $t$. All such agents have preferences representable by $E_{t} u\left(c_{2, t+1}\right)$ where $u$ is twice-continuously differentiable, strictly increasing, and strictly concave in its arguments. At points below, we will specialize to $u(c)=\left[c^{1-\phi}-1\right] /(1-\phi)$, with $\phi>0$, and $u(c)=\ln c$ when $\phi=1$.

The assets available to the agents are goods, which they may store, and fiat currency (money). If $\zeta>0$ units of the good are placed in storage at any date $t \geq 1$, then $x \zeta$ units are recovered from storage at date $t+1$, where $x>1$. The quantity of money in circulation at the end of period $t \geq 1$, per young agent, is denoted $M_{t}$. Let $0<p_{t}<\infty$ denote the price level at date $t$. Let $\frac{p_{t+1}}{p_{t}} \equiv \pi_{t}$ denote the inflation rate between period $t$ and $t+1$. Then the gross real rate of return on money $\left(R_{m, t}\right)$ between period $t$ and $t+1$ is given by $R_{m, t} \equiv p_{t} / p_{t+1}=\frac{1}{\pi_{t}}$. Also, let $m_{t} \equiv M_{t} / p_{t}$ denote real money balances at date $t$, and $I_{t} \equiv \frac{x}{R_{m, t}}=x \pi_{t}$ denote the gross nominal interest rate between $t$ and $t+1$. Note that $I_{t}$ represents the opportunity cost of cash relative to storage. We assume that money is a "bad" asset; when $R_{m, t}$ is non-stochastic, this translates into the assumption that

$$
x>R_{m, t} \text { for all } t
$$

holds; eq. (1) will later be mapped into a restriction on the set of constant money growth policies.

In addition to the store-of-value function of money, spatial separation and limited communication generate a transactions role of money as in Townsend (1987). As 
such, money can be valued even if it is dominated in return by storage. The details are outlined below and follow standard conventions setup in Schreft and Smith (1997) or more recently in Haslag and Martin (forthcoming).

\subsection{Random relocation}

Each period, a (potentially stochastic) fraction $\alpha$ of the young agents is relocated to the other location. We assume that the value of $\alpha$ is publicly known at the beginning of each period. However, an individual's relocation status is not known until the end of the period. In other words, at the start of each date, everyone knows how many will move, but no one knows who will move until the end of the period. An agent that is relocated cannot collect the return on any goods she has stored, or that have been stored on her behalf, since goods cannot be transported across locations. However, if an agent is carrying fiat currency when she is relocated, then the currency is relocated with it.

Under the circumstances, there are two strategies an agent can use to transfer income over time. First, she can save on her own, storing some quantity of goods and acquiring some quantity of fiat currency. The problem is that if she is relocated then she must abandon her stored goods, and if not, then she is stuck holding fiat currency, a "bad" asset (more below on this). Alternatively, she can deposit her entire endowment in a perfectly competitive bank. The bank pools the goods deposited by all the young agents and uses them to acquire a portfolio of stored goods and fiat currency. It issues claims to the agents whose nature, timing and size are contingent on their relocation status. If an agent does not get relocated, then she gets a return on her deposit next period that is funded by the goods the bank has stored. If she gets relocated, then she gets a return on her deposit in the same period that takes the form of a fiat currency payment (whose real value will depend on the following period's price level) funded by the bank's holdings of fiat currency. ${ }^{3}$ Since banks can pool individual risks, it can be checked that the latter strategy always dominates the former and we will analyze the economy on this basis. ${ }^{4}$ Monetary policy influences the bank's ability to provide risk sharing, an issue which lies at the heart of our

\footnotetext{
${ }^{3}$ Limited communication disallows banks from communicating in any way with banks on the other island; in particular, the bank may not "wire money" or issues checks etc.

${ }^{4}$ Relocation status is public information; concerns regarding bank runs do not appear here.
} 
analysis.

\subsection{Conduct of monetary policy}

Here, we allow the government to conduct monetary policy in one of two possible ways. The first, called "monetary targeting", is one where the government changes the nominal stock of fiat currency at a fixed non-stochastic gross rate $\mu>0$ per period, so that $M_{t}=\mu M_{t-1}$ for all $t$. The second, called "inflation targeting", is one where the government changes the nominal stock of fiat currency in such a way as to keep the long-run gross inflation rate fixed at $\pi$.

As an aside, also note that in this setting, since $I_{t} \equiv \frac{x}{R_{m, t}}=x \pi_{t}$ holds, nominal interest rate targeting and inflation targeting are identical instruments. Moreover, in steady states, money growth targeting and inflation targeting are equivalent. Below we will show that in the presence of shocks, money growth targeting and inflation targeting are very dissimilar.

All money injections are implemented through lump sum transfers $(\tau)$ to the young agents. The period $t$ budget constraint of the government is

$$
\tau_{t}=\frac{M_{t}-M_{t-1}}{p_{t}}=m_{t}-m_{t-1} R_{m, t-1}
$$

for all $t \geq 1$. Taxes and transfers to old agents are discussed later in Section 6.1.

\subsection{The bank's problem}

As a benchmark, it is useful to start by studying the bank's problem for the purely deterministic environment. As discussed earlier, the asset holdings of young agents are assumed to be costlessly intermediated by perfectly competitive banks. These banks hold portfolios of fiat currency and physical assets, which consist of stored goods. Every young agent deposits her after-tax/transfer income in the bank. The banks divide their deposits between stored goods $s_{t}$ and real balances of fiat currency $m_{t}$, so that

$$
w_{t}+\tau_{t}=m_{t}+s_{t}
$$

Define $\gamma_{t} \equiv \frac{m_{t}}{w_{t}+\tau_{t}}$ as the ratio of cash reserves to deposits. Banks announce a return of $d_{m, t}$ to each mover (one who gets relocated) and $d_{n, t}$ to each non-mover (one who 
stays on in the location she was born). These returns satisfy some constraints. First, relocated agents, of whom there are $\alpha_{t}$, have to be given money and so the bank has to use its holdings of cash reserves to pay them. Under assumption (1), it can be checked that banks will not hold cash reserves to pay non-movers. Consequently,

$$
\alpha_{t} d_{m, t} \leq \gamma_{t} R_{m, t}
$$

must hold, since money earns a return of $R_{m, t}=\frac{p_{t}}{p_{t+1}}$ between $t$ and $t+1$ (which the bank takes as given). Similarly, the promised return to the non-movers must satisfy

$$
\left(1-\alpha_{t}\right) d_{n, t} \leq\left(1-\gamma_{t}\right) x
$$

Additionally, $\gamma_{t} \in[0,1]$ must hold. Competition among banks for depositors will, in equilibrium, force banks to choose return schedules and portfolio allocations so as to maximize the expected utility of a representative depositor, subject to the equality versions of the constraints we have described. For future reference, define $c_{m, t} \equiv d_{m, t}\left(w_{t}+\tau_{t}\right)$ as the old-age consumption of each mover and $c_{n, t} \equiv d_{n, t}\left(w_{t}+\tau_{t}\right)$ as the old-age consumption of each non-mover.

If $w_{t}=w$ and $\alpha_{t}=\alpha \forall t$, i.e., the endowment and relocation probability are known and fixed (as in the standard deterministic random relocation model analyzed by Schreft and Smith (1997)), the bank's problem can be rewritten as

$$
\max _{\gamma_{t} \in[0,1]}\left\{\alpha u\left(\frac{\gamma_{t}}{\alpha} R_{m, t}\left(w+\tau_{t}\right)\right)+(1-\alpha) u\left(\frac{1-\gamma_{t}}{1-\alpha} x\left(w+\tau_{t}\right)\right)\right\} .
$$

The first order conditions for this problem are given by

$$
R_{m, t} \cdot u^{\prime}\left(c_{m, t}\right)=x \cdot u^{\prime}\left(c_{n, t}\right) \text { for } \gamma>0
$$

The bank equates the marginal rate of substitution between the two types to the marginal ratios of opportunity costs for their respective assets. Since $x>R_{m, t}$, it follows that $u^{\prime}\left(c_{m, t}\right)>u^{\prime}\left(c_{n, t}\right)$; it follows from the assumed concavity of $u$ that the bank's promised per unit return to each mover will be less than that of a nonmover. Since money is a poor asset and movers can use only money, their marginal utility of consumption is higher than that of the non-movers; indeed it is higher by a margin $x / R_{m, t}$. As we show below, a planner (appropriately constrained by limited communication) would set this margin to $x$. 
It is easily checked that the first order conditions to the problem in (6) for $u(c)=$ $\left[c^{1-\phi}-1\right] /(1-\phi)$ is given by

$$
R_{m, t}\left(\frac{\gamma_{t}}{\alpha} R_{m, t}\right)^{-\phi}=x\left(\frac{1-\gamma_{t}}{1-\alpha} x\right)^{-\phi}
$$

the solution to which is given by

$$
\gamma_{t}\left(I_{t}\right)=\frac{\alpha}{\alpha+(1-\alpha)\left(I_{t}\right)^{\frac{1-\phi}{\phi}}} .
$$

Notice that when $\phi=1$, the case of logarithmic utility studied extensively below, (9) reduces to

$$
\gamma_{t}=\alpha
$$

in this case, the bank's choice of the reserve-deposit ratio is independent of the nominal interest rate. Then $d_{m, t}=R_{m, t}$ and $d_{n, t}=x$ and the consumption of each mover is given by $R_{m, t}\left(w_{t}+\tau_{t}\right)$ while that of a non-mover is $x\left(w_{t}+\tau_{t}\right)$.

Several points deserve mention here. First, monetary policy influences the optimal $\gamma$ in the case of CRRA utility only insofar as it determines the relative return on money, $I_{t}$. Second, as is clear from (9), for all $I>1, \gamma \gtreqless \alpha$ iff $\phi \gtreqless 1$. Intuitively, think of the bank allocating its deposit base among two "goods", the consumption of movers and the consumption of non-movers. When the two are complements (substitutes) a low return on money relative to storage (i.e., $I>1$ ) requires that the share of current "income" allocated to consumption of movers be relatively high (low).

Finally, $\gamma^{\prime}(I) \gtreqless 0, \forall I$ iff $\phi \gtreqless 1$. An increase in $I$ has both income and substitution effects. First, it decreases the combined income available for consumption next period. However, for any fixed share $\gamma$, it affects movers relatively more. Thus, when the consumptions of movers and non-movers are complements, movers' share $\gamma$ must be increased. On the other hand, when the two consumptions are substitutes, it is better to shift consumption from movers to non-movers; hence, $\gamma$ should be lowered.

\subsection{Welfare and optimal monetary policy}

Below we first consider a steady state under monetary targeting, obtained by fixing a constant money growth rate, $\mu$. In the steady state inflation equals the money growth 
rate as real balance $m_{t}$ is constant for all $t$, i.e., $R_{m}=1 / \pi=1 / \mu$. Then, steady state welfare (indirect utility as a function of $R_{m}=\mu^{-1}$ ) for CRRA utility can be defined as

$$
W(\mu)=\frac{\{w+\tau(\mu)\}^{1-\phi}}{1-\phi}\left\{\alpha\left[\frac{\gamma(\mu)}{\alpha} \frac{1}{\mu}\right]^{1-\phi}+(1-\alpha)\left[\frac{(1-\gamma(\mu))}{1-\alpha} x\right]^{1-\phi}\right\}-\frac{1}{1-\phi},
$$

which, using (8), can be rewritten as

$$
W(\mu)=\max _{\mu} \frac{\{w+\tau(\mu)\}^{1-\phi}}{1-\phi}\left(\frac{1}{\mu}\right)^{1-\phi}\left(\frac{\gamma(\mu)}{\alpha}\right)^{-\phi}-\frac{1}{1-\phi}
$$

where $\tau(\mu)$ and $\gamma(\mu)$ are obtained from (2) and (9), respectively, as derived below.

Optimal monetary policy In steady state $(2)$ yields $\tau=\left(1-\frac{1}{\mu}\right) m$. Since $\gamma(w+\tau)=m$, we have $m=\gamma w /\left(1-\left(1-\frac{1}{\mu}\right) \gamma\right)$ and

$$
\tau=\left(1-\frac{1}{\mu}\right)\left[\frac{\gamma w}{1-\left(1-\frac{1}{\mu}\right) \gamma}\right]
$$

Since $I=x \mu$, we can rewrite (9) in steady states as

$$
\gamma=\frac{\alpha}{\alpha+(1-\alpha)(x \mu)^{\frac{1-\phi}{\phi}}}
$$

Then the problem of choosing the optimal ("steady state welfare maximizing") maximizing welfare given by (11) subject to (12) and (13). Observe that monetary targeting and inflation targeting are equivalent in steady state; this is seen by replacing $\mu$ with $\pi$ in (11), (12), and (13). We close this section with a fairly well-known result about optimal monetary policy in this environment, the proof of which may be found in Bhattacharya, Haslag, and Russell (2005).

Proposition 1 Under inflation targeting or equivalently under monetary targeting, irrespective of the degree of risk-aversion, the welfare maximizing policy is to hold the money stock fixed (zero inflation) if there are no shocks to endowments or liquidity preference. 
To understand the intuition behind this result, we construct a psuedo-planning problem (see Bhattacharya and Singh (2006) for details) in which the planner is restricted to choose among allocations that are feasible in the decentralized economy. If there is a monetary policy that allows the government in the decentralized economy to achieve this planning allocation, then clearly it is the optimal policy choice.

To that end, focus attention solely on steady states. In the decentralized economy, the assumption of limited communication prevents banks from using stored goods to pay movers, i.e., they have to keep aside some goods to "buy" the money to give to their moving clientele. In sum, the movers consume a portion of the current deposits and therefore such portion can not be stored. In the psuedo-planning problem, we constrain the planner similarly. ${ }^{5}$ In each period, the planner receives an endowment of $y$ goods in each island. At each island, he is constrained to use a portion of the current endowment to pay the newly arrived people from the other island (those who were born in the previous period and got relocated; there are $\alpha$ of them at each island). The rest he can store for distributing next period among non-movers born in the current period. The same sequence repeats the next period. ${ }^{6}$

Formally, at any date, such a planner who allocates $w$ between the movers and the non-movers would choose an allocation $\left(c_{m}, c_{n}\right)$ so as to maximize $\alpha u\left(c_{m}\right)+$ $(1-\alpha) u\left(c_{n}\right)$ subject to $\alpha c_{m}+(1-\alpha) c_{n} / x=w$; the first order condition would reduce to the following constrained efficiency condition:

$$
\frac{u^{\prime}\left(c_{m}\right)}{u^{\prime}\left(c_{n}\right)}=x
$$

This is the usual within-period MRS = MRT condition which, at points below, will be referred to as the "intratemporal efficiency" or "intragenerational efficiency" condition.

The government's objective, of course, is to choose a $\mu$ that maximizes stationary welfare in a decentralized equilibrium. In such an equilibrium involving money, using

\footnotetext{
${ }^{5}$ The unconstrained planner, of course, would store the entire endowment (something the banks under the limited communication assumption cannot) and equalize consumption across movers and non-movers by giving them $x w$ next period.

${ }^{6}$ It is important to note here that even though the planner in any period is trading off consumption of the old movers of the previous generation against the consumption of future non-movers of the current generation (who will consume only in the following period), assuming that the planner cares equally for each generation, this is equivalent to a consumption allocation problem for any single generation.
} 


$$
\begin{gathered}
R_{m}=\frac{1}{\mu},(7) \text { reduces to } \\
\frac{u^{\prime}\left(c_{m}\right)}{u^{\prime}\left(c_{n}\right)}=\mu x .
\end{gathered}
$$

Comparing (14) with (15) reveals the optimal monetary policy choice to be $\mu=1$.

As Bhattacharya, Haslag, and Russell (2005) argue, in an OG model, in steady states, every unit of goods devoted to holding money is a unit that is not devoted to acquiring storage; as such, the social opportunity cost of money is the return on storage. Optimality requires that the private opportunity cost of holding money be the same as the social opportunity cost of money. Of course, the private opportunity cost of money is the nominal interest rate, $I=x \mu$. Hence, $\mu=1$ is the best choice. ${ }^{7}$ Indeed, as Wallace (1980) and Bhattacharya, Haslag, and Russell (2005) point out, zero inflation often has the presumption of being the optimal monetary policy in monetary overlapping generation models.

In steady states, intratemporal efficiency is achieved with a fixed money stock (zero inflation). Since every period is exactly the same, the government faces a static problem and hence cares only about this intratemporal margin. With shocks, however, the government's problem is generically no longer static; an intertemporal (intergenerational) margin appears. Since shocks hit different generations asymmetrically, the government pays attention to providing some amount of intergenerational insurance. To achieve this, the government may opt to trade off intratemporal for intertemporal efficiency and this causes optimal monetary policy to deviate from the zero inflation policy. This is the subject matter of the next two sections.

\section{Endowment uncertainty}

We now analyze an economy that is identical to the one studied above, except that the endowment $w$ is assumed to be stochastic. For analytical convenience, we assume that $w$ is drawn each period from an i.i.d. distribution with a pdf $f(w)$ over support $[\underline{w}, \bar{w}], \underline{w}>0, \bar{w}<\infty$. We denote by $w^{e}$ the expected value of $w$, and by $\sigma_{w}^{2}$, its

\footnotetext{
${ }^{7}$ As Bhattacharya, Haslag, and Russell (2005) argue, in standard infinitely-lived agent models, the gross social opportunity cost of providing money is one so it is optimal for the gross private opportunity cost of holding money to be one - the "Friedman rule". In contrast, the social opportunity cost of providing money in OG models is $x$. This explains why the Friedman rule, $I=1$ or $\mu=1 / x$, is not the best monetary policy choice for the government in the model we study.
} 
variance. Shocks to the endowment represent real shocks. Our goal is to investigate how monetary policy should respond to real uncertainty.

Allocations under stationary rational expectations equilibrium Recall that at the point at which the bank solves its problem, the current endowment is known. But the realization of next period's endowment has not occurred yet. The bank indirectly cares about next period's endowment because the latter will potentially influence next period's money demand, hence the next period's price level and thus the return on money between this period and the next. In this sense, the bank cannot promise a fixed real return to the movers anymore. All it can do is to let movers know how much nominal balances are being kept aside for them. The bank knows the distribution for $w$ and forms expectations on the return on money conditional on $f(w)$; in a rational expectations equilibrium, these expectations are correct. We focus solely on long run stationary equilibria under which expectations are coordinated across time, i.e., expectations of one generation are validated by the behavior of the next and so on ad infinitum.

The bank's problem (assuming it never finds it optimal to carry cash across periods; see below) in general is described by

$$
\max _{\gamma_{t} \in[0,1]}\left\{\alpha E_{t}\left(u\left(\frac{\gamma_{t}}{\alpha} R_{m, t}\left(w_{t}+\tau_{t}\right)\right)\right)+(1-\alpha) E_{t}\left(u\left(\frac{\left(1-\gamma_{t}\right) x}{(1-\alpha)}\left(w_{t}+\tau_{t}\right)\right)\right)\right\},
$$

where $E_{t}$ is an expectations operator conditional on date $t$ information; in future $E$ will denote its unconditional (ex-ante) counterpart. Analogous to (7), the first order conditions for this problem are now given by

$$
E_{t}\left(u^{\prime}\left(c_{m, t}\right) \cdot R_{m, t}\right)=E_{t}\left(x \cdot u^{\prime}\left(c_{n, t}\right)\right) \Rightarrow E_{t}\left(u^{\prime}\left(c_{m, t}\right) \cdot R_{m, t}\right)=x E_{t}\left(u^{\prime}\left(c_{n, t}\right)\right)
$$

As in Smith (2002), we start by exploring in detail the analytically manageable case of logarithmic utility. We assume that the bank never finds it optimal to use a part of its cash reserves to pay non-movers. Below we will write down a sufficient condition, a stochastic analog to (1), under which this assumption will be validated. The bank's problem is now described by (since only $R_{m, t}$ depends on the realization of $\left.w_{t+1}\right)$

$\max _{\gamma_{t} \in[0,1]}\left\{\int_{\underline{w}}^{\bar{w}} \alpha \ln \left(R_{m, t}\right) f\left(w_{t+1}\right) d w_{t+1}+\alpha \ln \left[\frac{\gamma_{t}}{\alpha}\right]+(1-\alpha) \ln \left[\frac{\left(1-\gamma_{t}\right) x}{1-\alpha}\right]+\ln \left(w_{t}+\tau_{t}\right)\right\}$. 
Observe that since it knows the current period endowment and takes the return on money and the size of the transfer as given, the bank's choice of $\gamma$ will respond only to the second and the third terms of the previous expression. Then, the choice of $\gamma_{t}$ is given by

$$
\gamma_{t}=\alpha \text { for all } t,
$$

making the decision rule of the bank identical to that in the non-stochastic endowment case [see (10)].

Even though endowment uncertainty has the potential to affect the real return on money, under log utility, the choice of $\gamma$ is not influenced by this return. Indeed, the choice of $\gamma$ is not state-contingent. Intuitively, an increase in the uncertainty about the rate of return on money effectively increases its opportunity cost. But the income and substitution effects cancel each other out for logarithmic utility. This will not be the case in the more general CRRA formulation discussed below.

\subsection{Monetary targeting}

Under monetary targeting, the government fixes the money growth rate at $\mu$. Since $\tau_{t}=\frac{M_{t}-M_{t-1}}{p_{t}}=m_{t}\left(1-\frac{1}{\mu}\right)$ and $m_{t}=\gamma_{t}\left(w_{t}+\tau_{t}\right)$, we have $m_{t}=\gamma_{t} w_{t} /\left(1-\gamma_{t}\left(1-\frac{1}{\mu}\right)\right)$. Hence, the equilibrium return on money is given by

$$
R_{m, t}=\frac{m_{t+1}}{\mu m_{t}}=\frac{1}{\mu} \frac{\gamma_{t+1} w_{t+1}}{\gamma_{t} w_{t}} \frac{1-\gamma_{t}\left(1-\frac{1}{\mu}\right)}{1-\gamma_{t+1}\left(1-\frac{1}{\mu}\right)}
$$

which reduces to $R_{m, t}=\frac{1}{\mu} \frac{w_{t+1}}{w_{t}}$ since $\gamma_{t}=\alpha$ for all $t$. Notice since $w_{t+1}$ is not known at $t$, the bank cannot promise a fixed real return to the movers anymore. Eq. (19) captures the notion of price-level uncertainty, a feature that is absent in the literature on random relocation models.

Notice further that with $\gamma_{t}=\alpha$ for all $t, m_{t}=\alpha w_{t} /\left(1-\alpha\left(1-\frac{1}{\mu}\right)\right)$. Hence, the equilibrium money demand is a fixed non-stochastic fraction of the stochastic endowment; as such, the volatility of money demand is induced entirely by the volatility in 
the endowment. Finally, as $\tau_{t}=m_{t}\left(1-\frac{1}{\mu}\right)$, we have

$$
\tau_{t}=\left(1-\frac{1}{\mu}\right)\left[\frac{\alpha w_{t}}{1-\alpha\left(1-\frac{1}{\mu}\right)}\right]
$$

When $\mu=1, \tau_{t}=0$; in this case, from the ex-ante standpoint of the government, monetary policy does not contribute to the volatility of post-tax/transfer income, $\left(w_{t}+\tau_{t}\right)$. In that case, the only uncertainty that the bank faces would come from the return on money given by $R_{m, t}=\frac{1}{\mu} \frac{w_{t+1}}{w_{t}}$. When $\mu<1$ (a contractionary monetary policy is implemented), $\tau_{t}<0$ obtains, and so $w_{t}+\tau_{t}$ falls; i.e., the government imposes a lump-sum tax on all agents and uses the proceeds to retire some of the currency. Since less money "chases" the same amount of goods, the price level falls raising the return on money making storage less attractive. The fall in $w_{t}+\tau_{t}$ also contributes to less investment in storage.

Monetary policy has different effects on the two groups, movers and non-movers. The latter's consumption is given by $x\left(w_{t}+\tau_{t}\right)$ while the formers' by $R_{m, t}\left(w_{t}+\tau_{t}\right)$. For future reference, note that since $w_{t}+\tau_{t}=w_{t} /\left[1-\alpha\left(1-\frac{1}{\mu}\right)\right]$, the consumption of non-movers is given by $c_{n, t}=\frac{x w_{t}}{1-\alpha+\frac{\alpha}{\mu}}$ and that of the movers by $c_{m, t}=\frac{1}{\mu} \frac{w_{t+1}}{1-\alpha+\frac{\alpha}{\mu}}$.

We are now in a position to write down a sufficient condition on parameters under which the bank would not carry cash balances across periods (to pay non-movers).

Condition 1 If agents have logarithmic utility, then in the economy with i.i.d. endowment shocks, the bank will use currency only to pay the movers if and only if $x>\frac{w^{e}}{\mu \underline{w}}$ holds.

Now we are ready to evaluate welfare. Welfare at $t$ is obtained by evaluating (18) at $\gamma_{t}=\alpha$ and using the equilibrium return given by (19):

$W_{t}(\mu)=\alpha \int_{\underline{w}}^{\bar{w}}\left\{\ln w_{t+1}\right\} f\left(w_{t+1}\right) d w_{t+1}+(1-\alpha) \ln \left(x w_{t}\right)-\ln \left[1-\alpha\left(1-\frac{1}{\mu}\right)\right]-\alpha \ln \mu$.

Notice from (21) that monetary policy $(\mu)$ has no effect on the intertemporal margin (the first two terms on the r.h.s. of (21)). As such, as argued before, the presumption is still in favor of zero inflation being optimal since that would be intra and inter temporally efficient. 
Welfare under uncertainty We adopt an ex-ante measure of welfare, which in a stochastic overlapping generations economy with finitely lived agents, allows us to obtain the stochastic analog of the golden rule. Here, a generation's welfare is defined as its lifetime expected utility where an unconditional expectation is taken with respect to stationary distributions of exogenous as well as endogenous variables. This measure, by construction, treats all generations symmetrically and makes each of them "representative". The unconditional expectation ensures that the derived policy rules will be state-uncontingent or "timeless".

Formally, since $w$ is assumed to be drawn from a time-invariant i.i.d. distribution, ex-ante stationary welfare is defined as $W^{\mu} \equiv E\{W(\mu)\}=\int W f(w) d w$. Thus using (21) we have

$$
W^{\mu}=(1-\alpha) \ln x+\int_{\underline{w}}^{\bar{w}}\{\ln w\} f(w) d w-\ln \left[1-\alpha\left(1-\frac{1}{\mu}\right)\right]-\alpha \ln \mu
$$

What $\mu$ is the best from the standpoint of stationary welfare? We define $\tilde{\mu} \equiv$ $\arg \max \left\{W^{\mu}\right\}$. Since $W^{\mu}$ is assumed to be concave in $\mu, \tilde{\mu}$ solves $\frac{d}{d \mu} W^{\mu}=0$; [notice $\tilde{\mu}$ maximizes the last two terms in (22)]. For future reference, we define $\tilde{W}^{\mu} \equiv$ $\max _{\mu} W^{\mu}$.

Proposition 2 Under logarithmic utility, the optimal monetary policy is to keep the money supply fixed, i.e., $\tilde{\mu}=1$.

It is interesting to note that the optimal prescription for the money growth rate coincides with that in the economy with no real shocks studied in Section 2.5.

To see the intuition behind this result, it is useful to revisit the planner's problem in this environment. Analogous to the deterministic case discussed earlier, a planner who allocates $w$ between the movers and the non-movers would choose an allocation that leads to the ex-ante marginal condition

$$
\frac{E\left[u^{\prime}\left(c_{m}\right)\right]}{E\left[u^{\prime}\left(c_{n}\right)\right]}=x
$$

which is the "intratemporal efficiency" or the "intragenerational efficiency" condition. ${ }^{8}$ In the decentralized problem, recall the consumption of movers is given by

\footnotetext{
${ }^{8}$ Assume that the planner cares equally about each generation. In period $t$, after $w_{t}$ is realized,
} 
$c_{m}=\frac{1}{\mu} \frac{w}{1-\alpha+\frac{\alpha}{\mu}}$, and that of the non-movers by $c_{n}=\frac{x w}{1-\alpha+\frac{\alpha}{\mu}}$. Then, for log utility, it is easy to check that $\frac{E\left[u^{\prime}\left(c_{m}\right)\right]}{E\left[u^{\prime}\left(c_{n}\right)\right]}=x$ holds only when $\mu=1$. In other words, intratemporal efficiency is ensured at $\mu=1$. The question then arises: does cutting or raising $\mu$ from unity have any intertemporal benefits that may overwhelm the loss of deviating from intratemporal efficiency? As discussed earlier and clear from (21), monetary policy $(\mu)$ has no effect on the intertemporal margin and hence such an action has no benefits at all.

For future reference, note that when $\mu=1$ obtains, $c_{m}=w$ and $c_{n}=x w$ holds. Thus, in an ex-ante sense, both movers and non-movers face identical consumption/income uncertainty arising entirely out of the endowment uncertainty.

As we demonstrate below, unlike in the deterministic case, the prescription for optimal monetary policy will be different from zero inflation under inflation targeting.

\subsection{Inflation targeting}

Under inflation targeting, the government fixes the inflation rate at $\pi$. It follows that the real return to money is given by

$$
R_{m, t}=\frac{1}{\pi}
$$

Clearly in this case, any uncertainty about the rate of return on money is removed. The government conducts monetary policy via time-varying taxes and transfers to ensure money is an asset with a fixed real return.

Since $\tau_{t}=\frac{M_{t}-M_{t-1}}{p_{t}}=m_{t}-\frac{m_{t-1}}{\pi}$, we get $m_{t}=\gamma_{t}\left(w_{t}+\tau_{t}\right)=\gamma_{t}\left(w_{t}+m_{t}-\frac{m_{t-1}}{\pi}\right)$ implying

$$
m_{t}=-\frac{\gamma_{t}}{\left(1-\gamma_{t}\right) \pi} m_{t-1}+\frac{\gamma_{t}}{1-\gamma_{t}} w_{t}
$$

planner will allocate $c_{m, t-1}$ to movers from period $t-1$, and $c_{n, t}$ to current non-movers so as to maximize $\alpha u\left(c_{m, t-1}\right)+(1-\alpha) u\left(c_{n, t}\right)$ subject to $\alpha c_{m, t-1}+(1-\alpha) c_{n, t} / x=w_{t}$; then the first order condition to the planner's problem reduces to

$$
u^{\prime}\left(c_{m, t-1}\right)=x u^{\prime}\left(c_{n, t}\right) \text {. }
$$

Ex-ante this is equivalent to (23):

$$
E\left\{u^{\prime}\left(c_{m}\right)\right\}=x E\left\{u^{\prime}\left(c_{n}\right)\right\} .
$$


Notice that (25) represents an $\mathrm{AR}(1)$ process for real balances. With $\gamma_{t}=\alpha$, the autocorrelation parameter equals $-\alpha /(1-\alpha) \pi$ whereas $w_{t} \alpha /(1-\alpha)$ is a stochastic "forcing function". The invariant (long run) distribution for money balances will depend on $f(w)$ and $\pi$. Denote the stationary distribution by $\Omega(m ; f(w), \pi)$. A necessary condition for its existence is $\frac{\alpha}{(1-\alpha) \pi}<1$.

Denote the mean and variance of the stochastic process for $m$ defined in (25) with $\gamma_{t}=\alpha$ by $m^{e}$ and $\sigma_{m}^{2}$ respectively. Then it is easily checked that

$$
E(m) \equiv m^{e}=\frac{\alpha w^{e}}{1-\alpha+\frac{\alpha}{\pi}} ; \quad \sigma_{m}^{2} \equiv E\left\{\left(m-m^{e}\right)^{2}\right\}=\frac{\left(\frac{\alpha}{1-\alpha}\right)^{2} \sigma_{w}^{2}}{1-\left[\frac{\alpha}{(1-\alpha) \pi}\right]^{2}}
$$

Notice that $m^{e}$ rises with $\pi$ but $\sigma_{m}^{2}$ falls with $\pi$.

Evaluating (18) at $\gamma_{t}=\alpha$ and using (24) obtains

$$
W_{t}(\pi)=-\alpha \ln \pi+(1-\alpha) \ln x+\ln \left(w_{t}+\tau_{t}\right)=-\alpha \ln \pi+(1-\alpha) \ln x+\ln \left(\frac{m_{t}}{\alpha}\right)
$$

From (27), it is apparent that $\pi$ has two effects on welfare, one through its effect on the return on money (captured by the $-\alpha \ln \pi$ term above) and the other via its effect on post-tax/transfer income (captured by the $\ln \left(w_{t}+\tau_{t}\right)$ or $\ln \left(\frac{m_{t}}{\alpha}\right)$ terms above). As such, the government will have to pay attention not just to intratemporal but also to intertemporal efficiency when choosing $\pi$. Using (27), ex ante welfare is defined as

$$
W^{\pi} \equiv E(W(\pi))=-\alpha \ln \pi-\ln \alpha+(1-\alpha) \ln x+\int_{m}\{\ln m\} \Omega(m ; f(w), \pi) d m
$$

Notice that the last term on the r.h.s of (28) corresponds to $E\left(\ln \left(w_{t}+\tau_{t}\right)\right)$ or the mean value of log post tax income. We define the optimal inflation rate as $\tilde{\pi} \equiv$ $\arg \max \left\{W^{\pi}\right\}$ and its corresponding welfare as $\tilde{W}^{\pi} \equiv \max _{\pi}\left\{W^{\pi}\right\}$. Henceforth, we assume that $W^{\pi}$ is strictly concave in $\pi$; then $\tilde{\pi}$ solves $\frac{d}{d \pi} W^{\pi}=0$.

Proposition 3 Under logarithmic utility, optimal inflation targeting involves setting a positive inflation rate, or $\tilde{\pi}>1$ obtains.

The proof of Proposition 3 relies on a second-order Taylor approximation of the last term on the r.h.s of (28) around $m^{e}$. An intuition for this result is as follows. The first thing to note is that inflation targeting completely eliminates uncertainty concerning the rate of return on money. The only uncertainty that remains as such is 
the one in post-tax/transfer income. As is evident from (27) and (26), a risk-averse agent would prefer a high expected value for $\ln m$ and as little variability in it as possible. Since raising the inflation rate achieves both, it follows that choosing a positive inflation rate $(\pi>1)$ may be desirable.

We now argue that zero inflation $(\pi=1)$ would be intratemporally efficient but not so intertemporally. The idea is as follows. Consider a date $t$ that has a relatively high realization of the endowment $w_{t}$. As a result, the current money demand, $m_{t}$, is high. Since $w_{t-1}$ was lower, the amount of money balances being brought forward by the old movers (born at $t-1$ ) is relatively small. If the government wishes to preserve the return on money at $1 / \pi$, it will have to inject fresh money to supply the higher money demand at $t$. Now, movers from period $t$ will arrive in $t+1$ with a higher (relative to the mean) amount of money. If $w_{t+1}$ is closer to the mean, the amount allocated to storage in $t+1$, i.e., $w_{t+1}-\frac{m_{t}}{\pi}$, will be lower than the mean amount stored, and lower with $\pi=1$ as compared to $\pi>1$. Insofar as $\pi>1$ mitigates the intertemporal transmission of shocks, it may be desirable from the standpoint of intertemporal efficiency.

To clarify it further, notice that in order to give $\frac{m_{t}}{\pi}$ to date $t$ movers the government will have to tax the date $t+1$ young such that their storage allocation, $(1-\alpha)\left(w_{t+1}+\tau_{t+1}\right)$, leaves $\frac{m_{t}}{\pi}$ of goods for date $t$ mover's consumption. In other words, taxes/transfers should be such that $(1-\alpha)\left(w_{t+1}+\tau_{t+1}\right)=w_{t+1}-\frac{m_{t}}{\pi}$. This is the rationale behind (25), which is rewritten below as (recall $\gamma_{t}=\alpha$ )

$$
\left(w_{t+1}+\tau_{t+1}\right)=-\frac{\alpha}{(1-\alpha) \pi}\left(w_{t}+\tau_{t}\right)+\frac{1}{1-\alpha} w_{t+1}
$$

Equation (29) makes clear that the autocorrelation between total income at two adjacent periods is negative and the strength of this correlation becomes smaller as $\pi$ rises. Thus setting $\pi>1$ may improve intertemporal efficiency; this way shocks to income get transmitted over time in a more muted fashion.

We now proceed to answer the question: given the real shocks to endowment, what should a benevolent government do, target the money growth rate (and set the net money growth rate to zero) or target a positive inflation rate? which action would generate the higher aggregate welfare? 
Proposition 4 Under logarithmic utility, optimal targeting of the money growth rate is stationary-welfare superior to optimal targeting of the inflation rate.

Recall that optimal monetary targeting involves setting $\mu=1$ (fixing the money supply) thereby making the post-tax/transfer income exactly equal to the endowment. In this setting, as discussed earlier, both non-movers' and movers' consumption variability is solely due to the endowment uncertainty. On the other hand, optimal inflation targeting involves fixing the inflation rate thereby eliminating any uncertainty with respect to the return on money; the residual uncertainty, in this case, is with regard to the post-tax/transfer income.

Why is monetary targeting superior? A fixed money supply rule achieves ex-ante intratemporal efficiency; it does/can not affect the endowment uncertainty, captured by $\sigma_{w}^{2}$. Compare this to a zero net inflation rate policy. Of course, as we have seen, $\pi=1$ can achieve ex-ante intratemporal efficiency; however, it is associated with a higher volatility of post-tax income, since the variance of post-tax income at $\pi=1$ (denoted $\left.\sigma_{w+\tau}^{2}\right|_{\pi=1}$ ) is $\left.\sigma_{w+\tau}^{2}\right|_{\pi=1}=\frac{\sigma_{w}^{2}}{1-2 \alpha}>\sigma_{w}^{2}$. Any $\pi>1$ would distort intratemporal efficiency but would be associated with reduced post tax income volatility. However, the volatility of post-tax income still exceeds that under monetary targeting since

$$
\left.\sigma_{w+\tau}^{2}\right|_{\pi>1}=\frac{\sigma_{w}^{2}}{1-2 \alpha+\alpha^{2}\left(1-\frac{1}{\pi^{2}}\right)}>\left.\sigma_{w+\tau}^{2}\right|_{\pi=1}=\frac{\sigma_{w}^{2}}{1-2 \alpha}>\sigma_{w}^{2}
$$

holds for all $\pi$. Overall, relative to monetary targeting, optimal inflation targeting distorts the intratemporal efficiency margin and leaves post-tax/transfer income more volatile.

\section{Liquidity shocks}

We now pursue another variation on the standard random relocation model by introducing liquidity shocks. Specifically, we assume that $\alpha_{t}$, the fraction of young agents relocating to the other location, is drawn each period from an i.i.d. distribution $g(\alpha)$ with support $[\underline{\alpha}, \bar{\alpha}]$. Denote by $\alpha^{e}$ the expected value of $\alpha$ and by $\sigma_{\alpha}^{2}$ its variance. As described earlier, shocks to $\alpha$ represent money demand or liquidity shocks. We assume that the value of $\alpha$ is publicly known at the beginning of each period. 9

\footnotetext{
${ }^{9}$ Smith (2002) and Antinolfi, Huybens, and Keister (2001), and Antinolfi and Keister (2006) consider settings where such shocks are realized after the bank has made its portfolio decisions. In
} 
However, to motivate the continued need for banks, we assume that an individual's relocation status is not known until the end of the period. In other words, while everyone knows the aggregate fraction of movers at the start of a period, no one knows who will move until the end of the period.

Our goal as before is to investigate how monetary policy should respond to shocks to liquidity preference. Analogous to the setting with endowment uncertainty, the bank cares about next period's liquidity demand because it will potentially influence next period's price level and thus the return on money between this period and the next. As before, we assume the bank knows the distribution for $\alpha$ and forms expectations on the return on money conditional on $g(\alpha)$; in a stationary rational expectations equilibrium, these expectations are correct for all times. As we demonstrate below, the impact of such liquidity shocks is entirely different from the endowment shocks studied earlier, even though at first blush it may seem that they ought to have similar effects (after all, both shocks work through liquidity demand and the return on money).

As before, for analytical tractability and intuition building, we start by working through the case with logarithmic utility. Since our current focus is on shocks to liquidity, we hold $w$ fixed for all $t$. Just as before, we assume that the bank never finds it is optimal to use a part of its cash reserves to pay non-movers. Below we will write down a sufficient condition, analogous to that in Condition 1, under which this assumption will be validated. The bank's problem is now described by

$$
\max _{\gamma_{t}} \quad \alpha_{t} \int_{\underline{\alpha}}^{\bar{\alpha}} \ln R_{m t} g\left(\alpha_{t+1}\right) d \alpha_{t+1}+\alpha_{t} \ln \left(\frac{\gamma_{t}}{\alpha_{t}}\right)+\left(1-\alpha_{t}\right) \ln \left[\frac{1-\gamma_{t}}{1-\alpha_{t}} x\right]+\ln \left(w+\tau_{t}\right) .
$$

Note that bank's choice of $\gamma$ will only consider the second and the third term. It is easy to verify that the optimal choice of $\gamma_{t}$ is given by

$$
\gamma_{t}=\alpha_{t} \text { for all } t
$$

Now the choice rule for $\gamma$ is state-contingent irrespective of the monetary policy

such situations, "banking crises" may arise, i.e., if the realized value of the liquidity shock is "too high", the bank may run out of all its cash reserves and even be forced to prematurely liquidate storage. 
regime. This is an important difference with the corresponding problem with endowment shocks.

\subsection{Monetary targeting}

Under monetary targeting, the government fixes the money growth rate at $\mu$. The real return to money follows from (19):

$$
R_{m, t}=\frac{\alpha_{t+1}}{\alpha_{t}} \frac{1-\alpha_{t}\left(1-\frac{1}{\mu}\right)}{\mu\left[1-\alpha_{t+1}\left(1-\frac{1}{\mu}\right)\right]} .
$$

Also, since $\tau_{t}=\frac{M_{t}-M_{t-1}}{p_{t}}=m_{t}\left(1-\frac{1}{\mu}\right), m_{t}=\gamma_{t}\left(w+\tau_{t}\right)$, and $\gamma_{t}=\alpha_{t}$, we have $m_{t}=\alpha_{t} w /\left(1-\alpha_{t}\left(1-\frac{1}{\mu}\right)\right)$. In contrast to endowment shocks, equilibrium money demand now is a stochastic fraction of the non-stochastic endowment; as such, the volatility of money demand is induced entirely by the volatility in the share of the endowment going towards money and not by the endowment itself. Herein lies the crucial difference between the way the two types of shocks influence the economy. Finally, as $\tau_{t}=m_{t}\left(1-\frac{1}{\mu}\right)$, we have

$$
\tau_{t}=\left(1-\frac{1}{\mu}\right) \frac{\alpha_{t}}{1-\alpha_{t}\left(1-\frac{1}{\mu}\right)} w
$$

From (33), it follows that $w+\tau_{t}=w /\left[1-\alpha_{t}\left(1-\frac{1}{\mu}\right)\right]$, and hence As before, $\mu=1$ would render $\tau_{t}=0$ (set the inflation tax rate to zero) thereby removing any income uncertainty.

We now write down a sufficient condition on parameters under which the bank would not carry cash balances across periods (to pay non-movers).

Condition 2 Under logarithmic utility, the bank never finds it optimal to use a part of its cash reserves to pay non-movers if

$$
x>\frac{1}{\mu} E\left\{\frac{\alpha}{\underline{\alpha}} \frac{\mu-\underline{\alpha}(\mu-1)}{\mu-\alpha(\mu-1)}\right\}
$$

holds. 
Using (32), and after some algebra, we can write indirect utility as

$$
\begin{aligned}
& W_{t}(\mu)=\alpha_{t} \int_{\underline{\alpha}}^{\bar{\alpha}} \ln \left[\frac{\alpha_{t+1}}{1-\alpha_{t+1}\left(1-\frac{1}{\mu}\right)}\right] g\left(\alpha_{t+1}\right) d \alpha_{t+1}+\left(1-\alpha_{t}\right) \ln x \\
& +\ln w-\alpha_{t} \ln \alpha_{t}-\left(1-\alpha_{t}\right) \ln \left[1-\alpha_{t}\left(1-\frac{1}{\mu}\right)\right]-\alpha_{t} \ln \mu .
\end{aligned}
$$

Notice that monetary policy, unlike in the corresponding economy with endowment shocks, can affect the intertemporal margin here via its effect on the first term on the r.h.s of (34). Hence, there would no longer exist a presumption in favor of a zero money growth rate being optimal. It can be checked that ex ante welfare, defined as $W^{\mu} \equiv E\{W(\mu)\}=\int W g(\alpha) d \alpha$, is given by

$$
\begin{aligned}
& W^{\mu}=\left(1-\alpha^{e}\right) \ln x+\ln w-\alpha^{e} \ln \mu \\
& -\int_{\underline{\alpha}}^{\bar{\alpha}}\left\{\left(\alpha-\alpha^{e}\right) \ln \alpha+\left(1-\left(\alpha-\alpha^{e}\right)\right) \ln \left[1-\alpha\left(1-\frac{1}{\mu}\right)\right]\right\} g(\alpha) d \alpha .
\end{aligned}
$$

Since $W^{\mu}$ is assumed to be concave in $\mu$, the optimal money growth rate $\tilde{\mu}$ solves $\frac{d}{d \mu} W^{\mu}=0$. It follows that $\tilde{\mu}$ is implicitly defined by

$$
\tilde{\mu}=\frac{1}{\alpha^{e}} \int_{\underline{\alpha}}^{\bar{\alpha}} \frac{1-\left(\alpha-\alpha^{e}\right)}{1-\alpha\left(1-\frac{1}{\tilde{\mu}}\right)} \alpha g(\alpha) d \alpha .
$$

Proposition 5 In the presence of liquidity shocks, the optimal monetary target involves a negative net money growth rate, i.e., $\tilde{\mu}<1$.

In this setup, monetary policy has different effects on the two groups, movers and non-movers. The latter's consumption is given by $x\left(w+\tau_{t}\right)$ while the formers' is given by $R_{m, t}\left(w+\tau_{t}\right)$. A constant money supply, unlike in the case of real endowment shocks, is no longer optimal. Why? At $\mu=1$, the consumption of non-movers is simply $x w$ while that of the movers (using (32)) is $\frac{\alpha_{t+1}}{\alpha_{t}} w$. As before, intragenerational efficiency requires that $E\left\{u^{\prime}\left(c_{m}\right)\right\}=x E\left\{u^{\prime}\left(c_{n}\right)\right\}$. However, in this setting $E\left\{u^{\prime}\left(c_{m}\right)\right\}=$ $\frac{1}{w} E\left\{\frac{\alpha_{t}}{\alpha_{t+1}}\right\}>\frac{1}{w}$, whereas $x E\left\{u^{\prime}\left(c_{m}\right)\right\}=\frac{1}{w}$. Thus, in the decentralized equilibrium $E\left\{u^{\prime}\left(c_{m}\right)\right\}>x E\left\{u^{\prime}\left(c_{n}\right)\right\}$ obtains. Thus, even though $\mu=1$ ensures a constant posttax/transfer income of $w$, the uncertain return on money makes the movers' expected marginal utility of consumption higher than what intergenerational efficiency requires. 
This makes a case for transferring some income to movers by cutting $\mu$ below 1 . Doing so, however, comes with a cost; since $\mu<1$ implies $\tau<0$, such an action by transferring income to the old lowers overall income $(w+\tau)$ of the young, and reduces storage investment. Since movers have a higher expected marginal utility of consumption, the social benefit obtained by such a transfer may overwhelm the cost of lowered overall income and reduced consumption of non-movers due to lower storage investment.

\subsection{Inflation targeting}

Under inflation targeting, the government fixes the inflation rate at $\pi$. It follows that the real return to money is given by (24). In this case, using (30), indirect utility reduces to

$$
W_{t}=-\alpha_{t} \ln \pi+\left(1-\alpha_{t}\right) \ln x+\ln \left(\frac{m_{t}}{\alpha_{t}}\right) .
$$

With $\gamma_{t}=\alpha_{t}$ in $(25)$, we now have

$$
m_{t}=-\frac{\alpha_{t}}{\left(1-\alpha_{t}\right) \pi} m_{t-1}+\frac{\alpha_{t}}{1-\alpha_{t}} w
$$

The invariant (long run) distribution for money balances will depend on $g(\alpha)$ and $\pi$. Denote the stationary distribution by $\Omega(m ; g(\alpha), \pi)$ with support $[\underline{m}, \bar{m}]$. A necessary condition for its existence is $\frac{\bar{\alpha}}{(1-\bar{\alpha}) \pi}<1$. Then, ex ante welfare is given by

$$
W^{\pi}=-\alpha^{e} \ln \pi-\left(1-\alpha^{e}\right) \ln x-\int_{\underline{\alpha}}^{\bar{\alpha}}\{\ln \alpha\} g(\alpha) d \alpha+\int_{\underline{m}}^{\bar{m}}\{\ln m\} \Omega(m ; g(\alpha), \pi) d m
$$

and as before the optimal inflation rate and the corresponding welfare are defined as $\tilde{\pi} \equiv \arg \max \left\{W^{\pi}\right\}$ and $\tilde{W}^{\pi} \equiv \max _{\pi}\left\{W^{\pi}\right\}$, respectively.

Proposition 6 In the presence of liquidity shocks, the optimal inflation target involves a positive net inflation rate, i.e., $\tilde{\pi}>1$.

The proof of Proposition 6 relies on a second-order Taylor approximation of the last term on the r.h.s of (39) around $m^{e}$. The intuition for this result closely follows 
the argument laid out in the endowment uncertainty case. As argued before, zero inflation $(\pi=1)$ would be intratemporally efficient but not so intertemporally. 10 Notice further that in order to give $\frac{m_{t}}{\pi}$ to date $t$ movers, the government will have to tax date $t+1$ young such that their storage allocation, $\left(1-\alpha_{t+1}\right)\left(w+\tau_{t+1}\right)$, leaves $\frac{m_{t}}{\pi}$ of goods for date $t$ mover's consumption. In other words, taxes/transfers should be such that $\left(1-\alpha_{t+1}\right)\left(w+\tau_{t+1}\right)=w-\frac{m_{t}}{\pi}$. Thus if $\alpha_{t+1}$ is around the mean the post-tax income in $t+1$ will be below the mean. This is the rationale behind (38), which can be rewritten as

$$
w+\tau_{t+1}=-\frac{\alpha_{t}}{\left(1-\alpha_{t+1}\right) \pi}\left(w+\tau_{t}\right)+\frac{1}{1-\alpha_{t+1}} w_{t+1} .
$$

The above makes clear that the autocorrelation between total income at two adjacent periods is negative and the strength of this correlation becomes smaller as $\pi$ rises. Thus setting $\pi>1$ maybe be a good idea from the standpoint of intertemporal efficiency. Doing so ensures that shocks to income get less transmitted over time.

Finally, we ask: in the presence of liquidity shocks, can we rank the two policy instruments in terms of welfare?

Claim 1 For any given $\frac{\sigma_{\alpha}}{\alpha^{e}}$, there exists an $\hat{\alpha}<1 / 2$ such that, $\tilde{W}^{\pi} \gtrless \tilde{W}^{\mu}$ for all $\alpha^{e} \lessgtr \hat{\alpha}$, where $\tilde{W}^{\pi}\left(\tilde{W}^{\mu}\right)$ is the maximized value of stationary welfare under inflation (money growth) targeting.

In other words, if the average number of movers is "small enough", inflation targeting does a better job. A rough intuition for this is as follows. As we have seen, optimal monetary targeting involves cutting $\mu$ below unity since such an action improves intragenerational efficiency. This comes at a cost; after all lowering $\mu$ diverts resources from being invested in storage for two reasons: a) cutting $\mu$ raises taxes and cuts post-tax income available for investment, and b) reducing $\mu$ raises the return on

\footnotetext{
${ }^{10}$ As before, consider a starting date $t$ at which the current fraction of movers $\left(\alpha_{t}\right)$ is realized to be relatively high and so the current money demand is high. Since $\alpha_{t-1}$ was lower, the amount of money balances being brought over by the old movers (born last period) is relatively small. For the government to preserve the return on money at $1 / \pi$, it will have to inject fresh money to supply this higher money demand. The movers from period $t$ will arrive in $t+1$ with a higher (relative to the mean) amount of money, and the amount of goods left for storage in $t+1, w-\frac{m_{t}}{\pi}$, will be lower than the mean. In sum, the higher the value of $\pi$, the less is the intertemporal transmission of shocks.
} 
money making storage less attractive. ${ }^{11}$ As a result of this reduced investment in storage, both movers and non-movers receive a relatively low level of consumption under monetary targeting. Inflation targeting, on the other hand, achieves intragenerational efficiency without shifting resources from non-movers to movers. Of course, because of the aforediscussed intertemporal transmission of shocks, inflation targeting also imposes a cost. It turns out if $\alpha^{e}$ is small enough (the "persistence" of shocks is not too high), i.e., its value does not generate near-unit root process for money balances, inflation targeting does a better job.

\section{Numerical results: extending to CRRA utility}

We have thus far produced a series of analytical results concerning money growth and inflation rate targeting using log utility. We now extend our analysis to incorporate the more general CRRA utility form: $u(c)=\left[c^{1-\phi}-1\right] /(1-\phi)$ where $\phi$ is the coefficient of relative risk aversion. Our objective here is to verify whether the flavor of the results from Section 3 and 4 continue to obtain for $\phi$ away from unity. Since it is not possible to pursue this analytically, we will resort to numerical analysis below.

First we briefly sketch the formulation of the bank and the government's problem for a general specification of shocks. Analogous to (6), we first rewrite the bank's problem in period $t$ as

$$
\max _{\gamma_{t} \in[0,1]}\left\{\frac{\left(w_{t}+\tau_{t}\right)^{1-\phi}}{1-\phi}\left(\alpha_{t}^{\phi} \gamma_{t}^{1-\phi} E_{t}\left\{R_{m, t}^{1-\phi}\right\}+\left(1-\alpha_{t}\right)^{\phi}\left[\left(1-\gamma_{t}\right) x\right]^{1-\phi}\right)-\frac{1}{1-\phi}\right\}
$$

where $E_{t}\{$.$\} denotes the expectation operator conditional on the information available$ at $t$. Notice $E_{t}\left\{R_{m, t}^{1-\phi}\right\} \equiv \int_{\underline{w}}^{\bar{w}}\left(R_{m, t}\right)^{1-\phi} f\left(w_{t+1}\right) d w_{t+1}$ in the case of the endowment shocks and $E_{t}\left\{R_{m, t}^{1-\phi}\right\} \equiv \int_{\underline{\alpha}}^{\bar{\alpha}}\left(R_{m, t}\right)^{1-\phi} g\left(\alpha_{t+1}\right) d \alpha_{t+1}$ for the case of liquidity shocks. The first order condition to the bank's problem leads to

$$
\gamma_{t}=\frac{\alpha_{t}}{\alpha_{t}+\left(1-\alpha_{t}\right)\left[E_{t}\left\{I_{t}^{\phi-1}\right\}\right]^{-\frac{1}{\phi}}}
$$

\footnotetext{
${ }^{11}$ As noted earlier the choice of $\gamma$ is invariant to $\mu$ under log utility. However, with a CRRA utility function with an elasticity of substitution greater than one, i.e., $\phi<1$, reducing $\mu$ will, in addition, increase $\gamma$ thus further reducing storage.
} 
For future reference, $\gamma^{e} \equiv E(\gamma)$.

Under monetary targeting using (19) $I_{t}=x / R_{m, t}$ is given by

$$
I_{t}=\mu x \frac{\gamma_{t} w_{t}}{\gamma_{t+1} w_{t+1}} \frac{1-\gamma_{t+1}\left(1-\frac{1}{\mu}\right)}{1-\gamma_{t}\left(1-\frac{1}{\mu}\right)}
$$

Thus, for given probability distributions for $\alpha$ and $w$, the equilibrium function $\gamma$ is obtained as a fixed point of (41). Evidently, under monetary targeting, the equilibrium $\gamma_{t}$ [denoted $\gamma_{t}(\mu)$ ] is a function of $\mu$, and the period $t$ realization of $\alpha$ and/or $w$. Under inflation targeting, however, $I_{t}=\pi x$ and the equilibrium $\gamma_{t}$ [denoted $\left.\gamma_{t}(\pi)\right]$ is readily obtained from $(41)$.

Let $i \in\{\pi, \mu\}$ denote the index for inflation rate and monetary growth targeting respectively. We can then write the indirect utility at $t$ as

$$
W_{t}(i)=\frac{1}{1-\phi}\left[x^{1-\phi}\left(1-\alpha_{t}\right)^{\phi}\left(w_{t}+\tau_{t}(i)\right)^{1-\phi}\left(1-\gamma_{t}(i)\right)^{-\phi}-1\right], \quad i \in\{\pi, \mu\} .
$$

As discussed earlier, under monetary targeting,

$$
w_{t}+\tau_{t}(\mu)=\frac{\gamma_{t}(\mu) w_{t}}{1-\gamma_{t}(\mu)\left(1-\frac{1}{\mu}\right)},
$$

whereas under inflation targeting, the post-tax income $w+\tau_{t}(\pi)$ is obtained as $\frac{m_{t}}{\gamma_{t}}$, where $m$ follows a stochastic process given by (see (25))

$$
m_{t}=-\frac{\gamma_{t}(\pi)}{1-\gamma_{t}(\pi)} \frac{1}{\pi} m_{t-1}+\frac{\gamma_{t}(\pi)}{1-\gamma_{t}(\pi)} w_{t} .
$$

The ex-ante stationary welfare under the two policies is expressed as

$$
W^{i} \equiv \frac{1}{1-\phi}\left[x^{1-\phi} E\left\{(1-\alpha)^{\phi}(w+\tau(i))^{1-\phi}(1-\gamma(i))^{-\phi}\right\}-1\right], \quad i \in\{\pi, \mu\},
$$

where the expectations are obtained under the stationary distribution of all variables. Next, the optimal policies and optimal welfare levels are defined as

$$
\tilde{W}^{i} \equiv \max _{i}\left\{W^{i}\right\}, \tilde{\imath} \equiv \arg \max \left\{W^{i}\right\}, \quad i \in\{\pi, \mu\}
$$

Finally, we represent $\tilde{W}^{i}$ in terms of its consumption equivalent $\tilde{c}^{i}$ by using

$$
\tilde{W}^{i}=\left[\left(\tilde{c}^{i}\right)^{1-\phi}-1\right] /(1-\phi) .
$$


Our choice of parametric specification is as follows. In the case of endowments shocks, we fix $\alpha=0.2$ and assume that $w$ is log-normally distributed. In particular, we assume $\ln w \sim N(-0.00166,0.0577)$. This implies $w^{e}=1, \sigma_{w}^{2}=0.00333$, and $\frac{\sigma_{w}}{w^{e}}=0.0577 .{ }^{12}$ In the case of liquidity shocks, we fix $w=1$ and assume that $\alpha$ is i.i.d. and uniformly distributed over $[0.18,0.22] .{ }^{13}$ This implies that $\alpha^{e}=0.2$ and $\frac{\sigma_{\alpha}}{\alpha^{e}}=0.0577$. Below, we compare optimal money growth and inflation rates under the two policies, along with their respective welfare levels, for $\phi \in[0.5,2.1] .{ }^{14}$

A few words about the computational algorithm is in order. Under monetary targeting, the main step entails computing the fixed point of $\gamma$ as a function of $w$ or $\alpha$, depending on the nature of the shock. To do so, we guess an initial function ${ }^{15}$, and numerically iterate on (41) to convergence. This is done for a fixed $\mu$. Once the $\gamma$ function is obtained, evaluating (44) is straightforward. By repeating this exercise for different values of $\mu$, we easily obtain $\tilde{\mu}$ and $\tilde{W}^{\mu}$. Under inflation targeting, however, the money supply (and hence the post-tax income) process (43), even under the assumption of a uniform distribution for $w$ and $\alpha$, does not yield an analytical closed form stationary distribution. Hence, we resort to simulations. Specifically, we first fix $\pi$. This yields $\gamma$ explicitly as a function of $w$ or $\alpha$. After assuming an initial value of $m_{0}=m^{e}$, we let the computer simulate (43), and for each observation of $\alpha$ or $w$, and $m$ compute (42). An average obtained from the previous step yields (44) simply by the law of large numbers. By repeating this exercise for different values of $\pi$, we obtain $\tilde{\pi}$ and $\tilde{W}^{\pi}$.

\subsection{Endowment shocks}

We now report on the optimal choices of the inflation rate and the money growth rate as they vary with risk aversion. Our earlier results have established that when

\footnotetext{
${ }^{12}$ The same mean and variance can be obtained with $w$ uniformly distributed over support $[0.9,1.1]$. The results under uniform distribution are almost identical to those for the log-normal distribution.

${ }^{13}$ The results have been checked with a log-normal distribution of $\alpha$ in which the mean and variances are kept equal to that under an uniform distribution, and the range of $\alpha$ is restricted to ensure $\alpha<0.5$. Once again, as in the case of endowment shocks, the results are almost identical.

${ }^{14} \mathrm{We}$ find that $\phi \in[0.5,2.1]$ is a fairly representative range, and the qualitative nature of our results continue to hold when this range is enlarged.

${ }^{15}$ Our initial guess is $\gamma\left(w_{t}\right)=\alpha$, or $\gamma\left(\alpha_{t}\right)=\alpha_{t}$. The convergence to the equilibrium function at any desired accuracy is reasonably fast.
} 
$\phi=1$ (log utility), we have $\tilde{\mu}=1$ and $\tilde{\pi}>1$. Figure 1 (a) shows that $\tilde{\pi}>1$ and $\tilde{\mu} \leq 1$ for all $\phi$. Figure 1(b) presents a sharper inset image to highlight that $\tilde{\mu}<1$ for all $\phi \neq 1$; for the latter however $\tilde{\mu}$ is relatively closer to one.

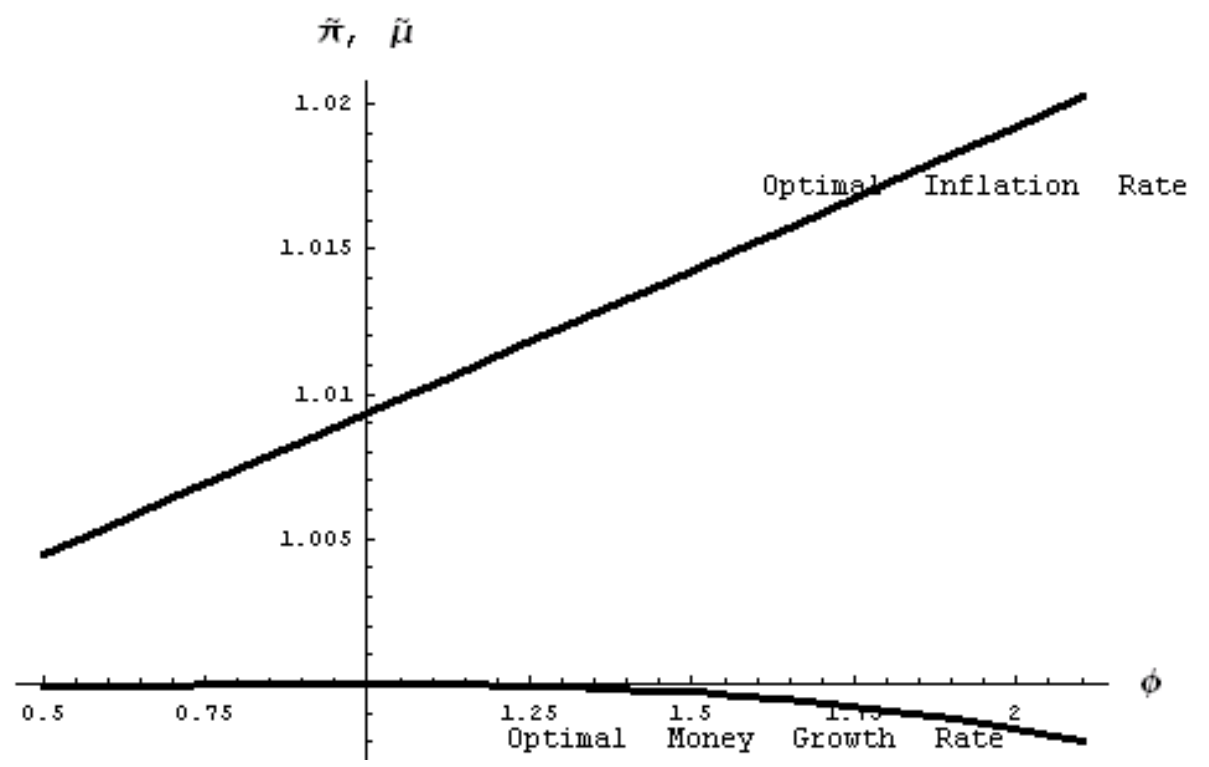

Figure 1a: Optimal $\pi$ and $\mu$ against $\phi$ under endowment shocks

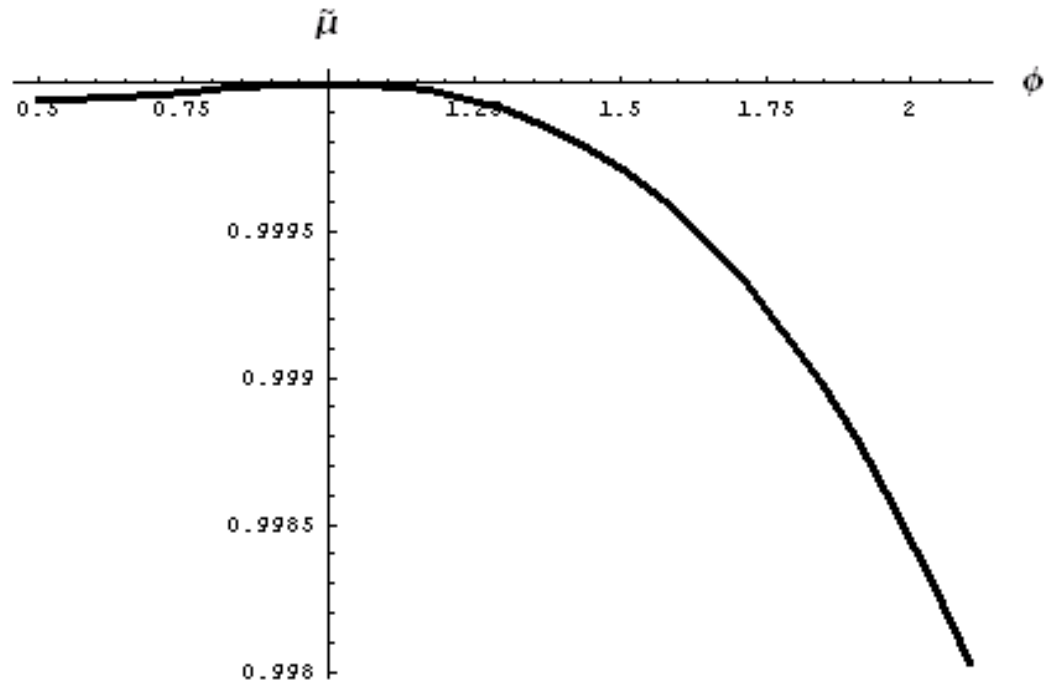

Figure 1b: (inset picture) Optimal $\mu$ against $\phi$ (endowment shocks)

A rough intuition for why $\tilde{\mu}<1$ obtains for all $\phi \neq 1$ is as follows. To begin with, 
consider the solution to the bank's problem in the deterministic case when $\phi \neq 1$. As is clear from (13), the bank would choose

$$
\gamma=\frac{\alpha}{\alpha+(1-\alpha)(x \mu)^{\frac{1-\phi}{\phi}}} .
$$

We know from Proposition 1 that in the deterministic case $\mu=1$ is best, implying that the bank's choice of the reserve-deposit ratio is given by

$$
\bar{\gamma} \equiv \frac{\alpha}{\alpha+(1-\alpha)(x)^{\frac{1-\phi}{\phi}}}
$$

The question is, why should the government want to deviate from $\mu=1$ in the corresponding economy with endowment shocks? The answer to this (discussed below) relies on two elements that distinguish the deterministic from the stochastic case. In the stochastic case, a) for $\phi \neq 1, \gamma$ is itself state-contingent causing the comovement of $\gamma$ and $w$ to be opposite in direction to the co-movement of $(1-\gamma)$ and $w$, henceforth the "comovement factor", and b) $\gamma^{e} \gtreqless \bar{\gamma}$ for $\phi \gtreqless 1$ implying that banks, on an average, allocate a higher (lower) share of deposits to money in the presence of shocks relative to their choice in the deterministic case for $\phi \gtreqless 1$, henceforth the "money share factor". ${ }^{16}$

The fact that $\gamma$ is contingent on $w$ implies that $\gamma w$ (consumption of all movers) and $(1-\gamma) w$ (consumption of all non- movers) will move differently. ${ }^{17}$ Specifically, the comovement of $\gamma$ and $w$ is opposite in direction to the comovement of $(1-\gamma)$ and $w$. This is because for $\phi>(<) 1, \gamma$ and $w$ are positively (negatively) correlated. Why? When $\phi>1$, and the current realized endowment is high (low), the current price level is lower (higher) than the average and banks expect a lower (higher) return on money, leading to a higher (lower) choice of $\gamma$. As a result, the consumption uncertainty of movers (relative to non-movers) is higher with $\phi>1$. Since the higher expected marginal utility of the movers implies that transfers of resources to them have a presumption of being desirable, an optimal monetary policy would call for transferring income from non-movers to movers by setting $\mu<1$. The reverse holds

\footnotetext{
${ }^{16} \gamma^{e} \gtreqless \bar{\gamma}$ for $\phi \gtreqless 1$ is easily verified from (41). Note first that $I_{t}=x \mu \frac{w_{t}}{w_{t+1}}$; thus $I_{t}$ is independent of $\phi$. By Jensen's inequality, $E\left\{I^{\phi-1}\right\} \gtreqless(E\{I\})^{\phi-1}$ for all $\phi \gtreqless 1$. Hence, for $\phi>1(<1)$ a mean preserving spread of the endowment process will raise (lower) $\gamma$.

${ }^{17}$ Recall at $\mu=1$, the currency carried by date $t$ movers purchases $c_{m, t}=\frac{\gamma_{t+1} w_{t+1}}{\alpha}$ units of consumption per mover, while each non-mover gets $c_{n, t}=\frac{\left(1-\gamma_{t}\right) x w_{t}}{1-\alpha}$ units to consume.
} 
true when $\phi<1$. Hence, the "co-movement factor" argument (part (a)) suggests that optimal $\mu \lesseqgtr 1$ for $\phi \gtreqless 1$.

However, the second factor, the "money share factor" (part (b)) calls for an opposite prescription. For example, when $\phi>1$, we have $\gamma^{e}>\bar{\gamma}$ implying that relative to the deterministic case, banks on an average allocate a higher share of their deposits to money balances potentially hurting non-movers. To compensate, the government ought to transfer income from movers to non-movers suggesting that optimal $\mu \gtreqless 1$ for $\phi \gtreqless 1$, the exact opposite of the prescription following the "comovement factor" argument. Our results indicate that the first "comovement factor" dominates the second "money share factor" for all $\phi>1$, while their relative effects reverse for $\phi<1$. For example, using the parametric specification described above, Figure 2 illustrates that the average slope (comovement) of $\gamma(w)$ for $\phi=2$ is higher relative to $\phi=0.5$. On the other hand, $\gamma^{e}-\bar{\gamma}=0.0029$ for $\phi=2$, while $\gamma^{e}-\bar{\gamma}=-0.0045$ for $\phi=0.5$.

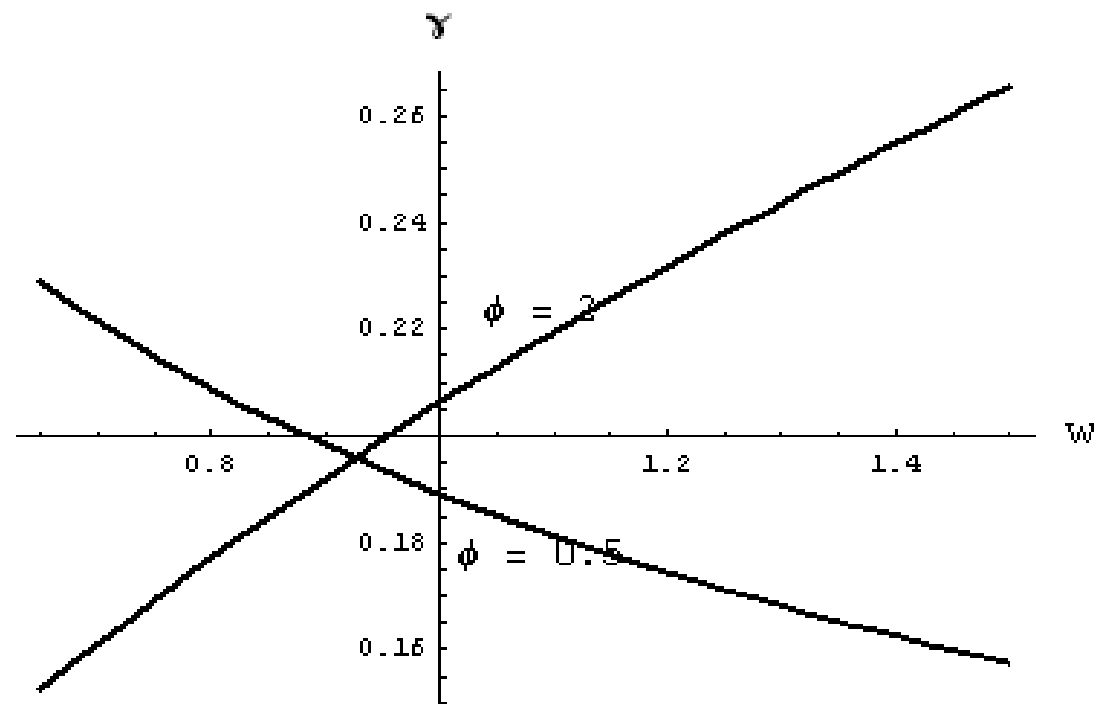

Figure 2: $\gamma$ as function $w$

To see why $\tilde{\pi}>1$, recall from our earlier discussion for log utility that a higher inflation target reduces the intertemporal volatility of income. It seems that as $\phi$ gets higher, the relative importance of reducing income volatility rises relative to the need of ensuring intragenerational efficiency. 
Figure 3 presents the percentage gain in steady state welfare, expressed in terms of equivalent consumption, that is obtained under monetary targeting relative to inflation targeting.

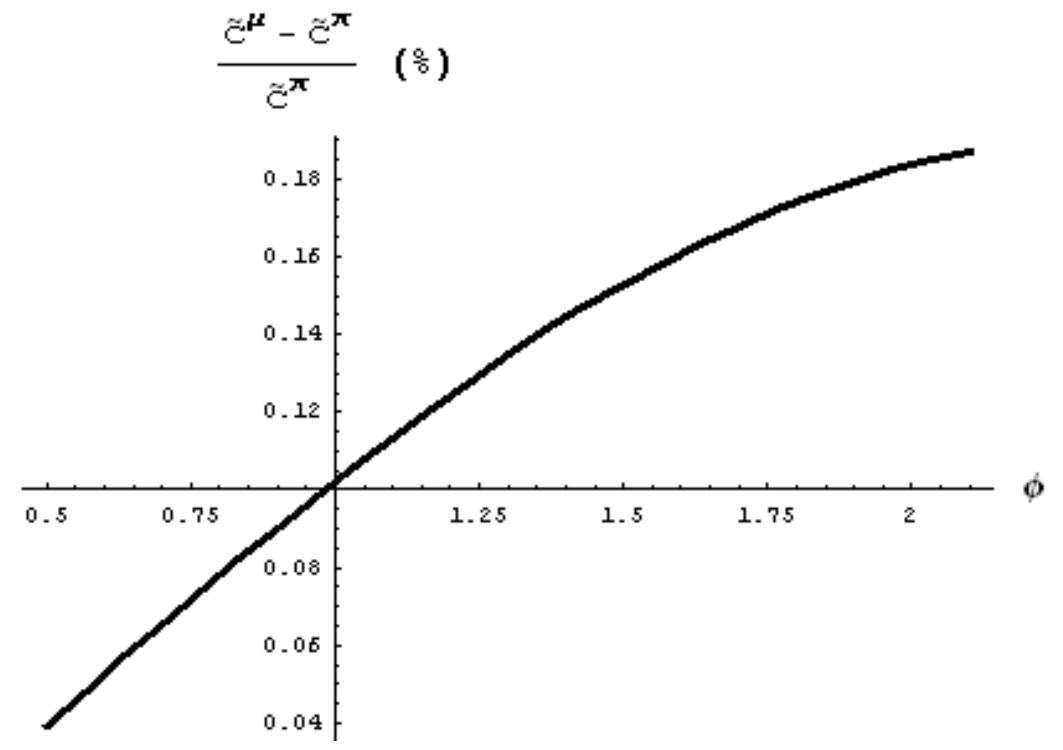

Figure 3: \% change in $\tilde{c}^{i}$ from following $\tilde{\mu}$ over $\tilde{\pi}$

Monetary targeting is more desirable relative to inflation targeting as $\phi$ increases. Our earlier analysis with log utility showed that inflation targeting generates a higher intertemporal income volatility. As $\phi$ increases, income volatility hurts even more, thus making monetary targeting even more desirable. The opposite is the case when $\phi<1$.

\section{$5.2 \quad$ Liquidity shocks}

Figure 4 below combines optimal money growth and inflation rates in the case of liquidity shocks for a range of $\phi$. The main upshot of the figure is that $\tilde{\mu} \leq 1$ and $\tilde{\pi}>1$ as $\phi \lesseqgtr 1$; optimal monetary targeting always involves implementing a nonexpansionary monetary policy while optimal inflation targeting always involves a 
expansionary policy.

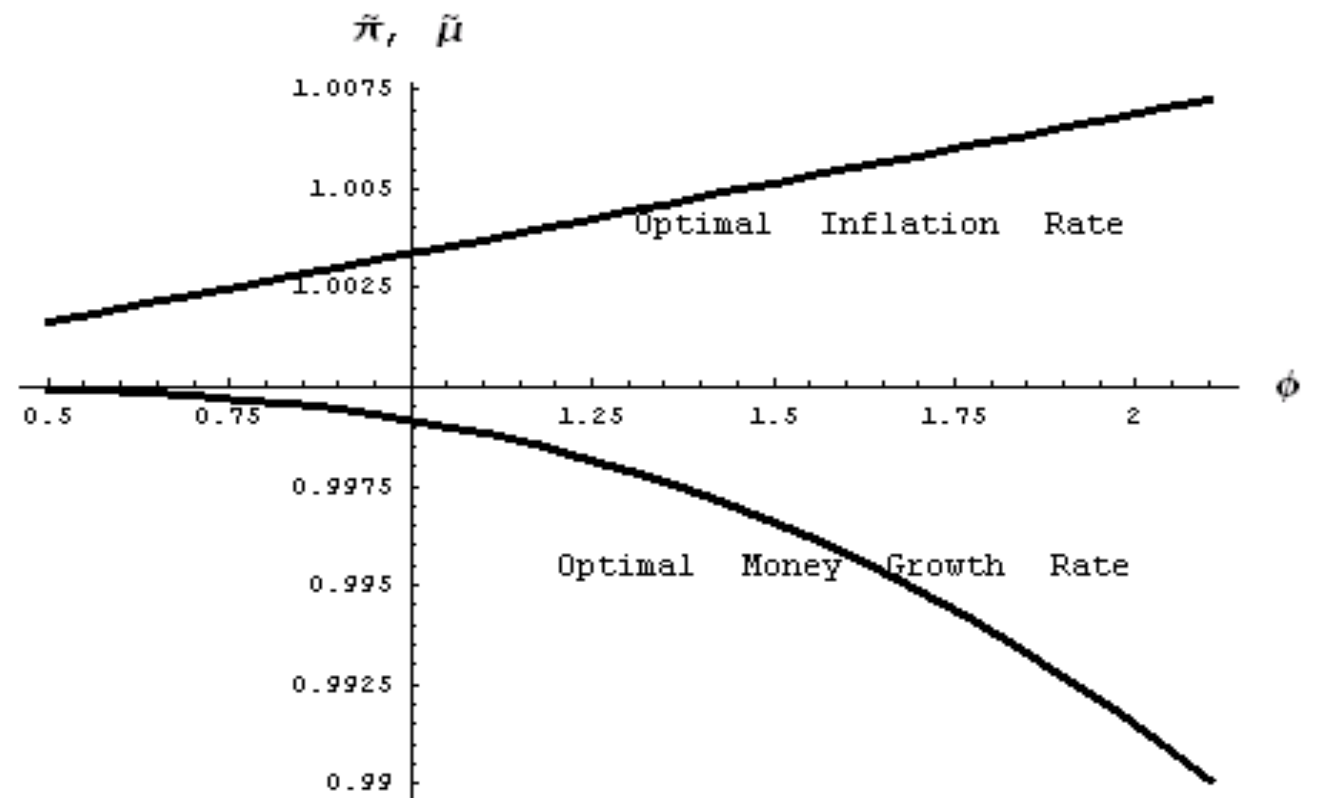

Figure 4: Optimal $\pi$ and $\mu$ against $\phi$ (liquidity shocks)

A rough intuition is as follows. At $\mu=1$, the consumption of each mover is given by $\frac{\gamma_{t+1}}{\alpha_{t}} w$, while that of each non-mover is $\frac{1-\gamma_{t}}{1-\alpha_{t}} x w$. It is evident that movers' consumption is more volatile than that of non-movers. ${ }^{18}$ Recall from our discussion under log utility that transferring income to movers by cutting $\mu$ ensures intragenerational efficiency. The need for intragenerational insurance becomes stronger as $\phi$ increases. Hence, a higher reduction in $\mu$ is required for larger values of $\phi$. The intuition behind an increasing relationship between $\tilde{\pi}$ and $\phi$ is similar to that under endowment shocks.

Finally, Figure 5 shows the percentage loss in steady state welfare, expressed in terms of equivalent consumption, under monetary targeting relative to inflation

\footnotetext{
${ }^{18}$ When $\phi=1$ ( $\log$ utility), the consumption of each mover is given by $\frac{\alpha_{t+1}}{\alpha_{t}} w$, while that of each non-mover is $x w$ which is non-stochastic. For general $\phi$, the consumption of nonmovers will be stochastic but not as volatile as that of the movers.
} 
targeting.

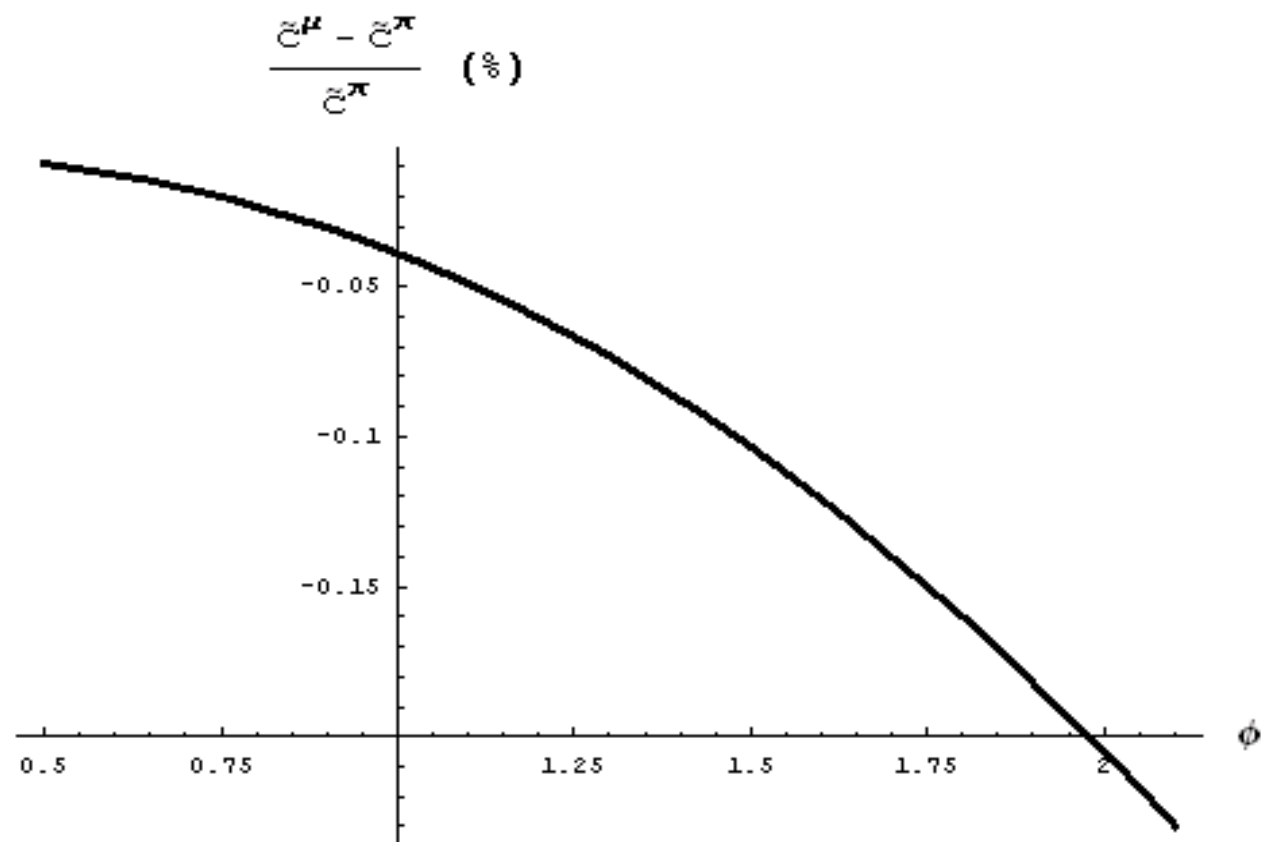

Figure 5: \% change in $\tilde{c}^{i}$ from following $\tilde{\mu}$ over $\tilde{\pi}$

A rough intuition for this follows the discussion after Proposition 1. Here, under monetary targeting a higher $\phi$ will imply that $\tilde{\mu}$ will have to be lowered "a lot" (as evident from Figure 4), which, as discussed earlier can be costly in terms of lost income from storage. Thus, the desirability of inflation targeting increases with $\phi$.

\section{Extensions}

\subsection{State-contingent rules}

Thus far, we have worked under the assumption that the benevolent central bank chooses, at the start of time, either a money growth rate or a inflation rate and intervenes no further. How would our analysis get amended if the central bank could control its desired monetary policy instrument every period after observing the realization of the shock? Clearly, in that case, the policy rules will in general depend on the history of shocks. In our environment, however, the rules will be solely contingent on the current period shock as the shocks being considered are i.i.d. 
Below, we solve for such rules. As shown by Bhattacharya and Singh (2007), solving a constrained planning problem turns out to be analytically much simpler in such environments. ${ }^{19}$ Therefore, we will first compute the allocations under a constrained planning problem and then work out the implied state-contingent rules.

Before we formulate a constrained planning problem, we will first need to review the equilibrium constraints of the decentralized economy. Recall that in the decentralized equilibrium, irrespective of the monetary policy chosen, movers born in the previous period purchase goods out of the current period endowment. The remaining gets stored, all of which is consumed by the non-movers. In other words, goods consumed by ultimate movers cannot be stored; conversely, movers cannot consume stored goods. In a constrained planning problem, the planner must be accordingly constrained to allocate consumption (denoted $c_{m, t-1}$ ) to the previous period's movers from the current endowment $\left(w_{t}\right)$ and store the rest $\left(s_{t}\right)$ to be given as consumption (denoted $c_{n, t}$ ) next period to the current period's non-movers (of measure $\alpha_{t}$ ).

The planner's date $t$ constraint can then be written as

$$
\begin{aligned}
& \alpha_{t-1} c_{m, t-1}=w_{t}-s_{t}, \\
& c_{n, t}=\frac{s_{t} x}{1-\alpha_{t}} .
\end{aligned}
$$

Under the planner's allocation, the indirect utility of a representative household is given by:

$$
u_{t}^{p} \equiv \alpha_{t-1} u\left(\frac{w_{t}-s_{t}}{\alpha_{t-1}}\right)+\left(1-\alpha_{t}\right) u\left(\frac{s_{t} x}{1-\alpha_{t}}\right) .
$$

The planner's problem then reduces to ${ }^{20}$

$$
\max _{\left\{s_{t}\right\}} E_{t} \sum_{k=0}^{\infty} u_{t+k}^{p} .
$$

\footnotetext{
${ }^{19}$ Bhattacharya and Singh (2007) describe the construct of a constrained planning problem as follows: "Consider a decentralized economy with a specified set of markets, rules of trade, an equilibrium concept, and a policy regime (a restricted set of policies). Such a specification of markets and rules of the game generates a set of equilibrium allocations that are attainable by a policymaker in the decentralized economy from within that policy regime. One can then set up a much simpler pseudo-planning problem in which the planner is restricted to choose from a set that contains (and may potentially be larger than) the aforementioned set of equilibrium allocations in the decentralized economy. Call the solution to this constrained planning problem the constrained planning solution. Among policies in the policy regime, if there is one that allows the decentralized economy to achieve the same allocation as under the constrained planning solution, it is the optimal policy."

${ }^{20}$ Under our formulation, each generation is equally weighted. With no time discounting, technically, the summation is not defined. However, as it turns out below, the planner's problem is static and therefore this issue can be safely ignored.
} 
Since $s_{t}$ matters only for $u_{t}^{p}$, it is easy to see that the planner's problem is essentially a one period problem. The optimal choice of $s_{t}$ is then simply characterized by

$$
u^{\prime}\left(\frac{w_{t}-s_{t}}{\alpha_{t-1}}\right)=x u^{\prime}\left(\frac{s_{t} x}{1-\alpha_{t}}\right),
$$

which for log utility reduces to

$$
\frac{\alpha_{t-1}}{w_{t}-s_{t}}=\frac{1-\alpha_{t}}{s_{t}}
$$

Recall that in the decentralized equilibrium $\gamma_{t}\left(w_{t}+\tau_{t}\right)$ is reserved by banks as cash while $\left(1-\gamma_{t}\right)\left(w_{t}+\tau_{t}\right)$ is stored; also $\gamma_{t}=\alpha_{t}$ for all $t$. Then to implement (46) using a state-contingent money growth rule, $\tau_{t}$ must satisfy

$$
\frac{\alpha_{t-1}}{w_{t}-\left(1-\alpha_{t}\right)\left(w_{t}+\tau_{t}\right)}=\frac{1}{w_{t}+\tau_{t}}
$$

which using $w_{t}+\tau_{t}=w_{t} /\left(1-\alpha_{t}\left(1-\frac{1}{\mu_{t}}\right)\right)$ yields the following state-contingent rule

$$
\mu_{t}=\frac{\alpha_{t}}{\alpha_{t-1}}
$$

Two features of this rule are worth discussing. First, when the measure of current period movers is relatively large, i.e., $\left(\alpha_{t}>\alpha_{t-1}\right)$, a monetary injection is desirable. Intuitively, the best that such a rule can do is equalize the marginal utilities of movers of the past generation with that of the non-movers from the current generation. Under log utility, this amounts to allocating $w_{t}$ equally across a population of $1-$ $\alpha_{t}+\alpha_{t-1}$. Thus, the rule allocates an amount $w_{t} /\left(1-\alpha_{t}+\alpha_{t-1}\right)$ to each individual; given directly to the movers for consumption and stored for the non-movers. In the decentralized equilibrium, per non-mover storage is $w_{t}+\tau_{t}=\frac{w_{t}}{1-\alpha_{t}\left(1-\frac{1}{\mu_{t}}\right)}$. Setting $\mu_{t}=\frac{\alpha_{t}}{\alpha_{t-1}}$ thus obtains the best, i.e., it decentralizes what a constrained planner can.

Second, the rule is independent of shocks to the endowment process. Indeed, in the absence of liquidity shocks, the best policy would be to set $\mu_{t}=1$ for all $t$. In other words, when there are no shocks to liquidity, it is best to fix the money supply. ${ }^{21}$ This

\footnotetext{
${ }^{21}$ Observe that (47) can be equivalently implemented through a state-contingent inflation-rate rule in the following way. If the only shocks are those to the endowment process, (47) implies $\mu=1$; then$$
\pi_{t}=\frac{m_{t-1}}{m_{t}}=\frac{w_{t-1}}{w_{t}}
$$ 
statement has an important implication: in the sole presence of endowment shocks, the state contingent money supply rule coincides with the state uncontingent money supply rule (monetary targeting).

How do monetary targeting and inflation targeting fare against the corresponding state-contingent rules in the case of liquidity shocks? Substituting equation (46) in (45), one obtains

$$
c_{m, t}=\frac{w}{1-\alpha_{t+1}+\alpha_{t}} ; \quad c_{n, t}=\frac{w}{1-\alpha_{t}+\alpha_{t-1}} x .
$$

Denote $\tilde{W}_{t}^{s c}$ as the welfare of generation $t$ under the state contingent rule. Then, ex-ante welfare is given by

$$
E\left\{\tilde{W}_{t}^{s c}\right\} \equiv E\left\{\begin{array}{c}
\alpha_{t} \ln w+\left(1-\alpha_{t}\right) \ln w+\left(1-\alpha_{t}\right) \ln x \\
-\alpha_{t} \ln \left(1-\alpha_{t+1}+\alpha_{t}\right)-\left(1-\alpha_{t}\right) \ln \left(1-\alpha_{t}+\alpha_{t-1}\right)
\end{array}\right\} .
$$

We are now in a position to state the main result of this section.

Proposition 7 In the sole presence of endowment shocks, the state contingent rule coincides with the state uncontingent monetary targeting rule. In the sole presence of liquidity shocks, the state contingent rule strictly welfare dominates the state uncontingent inflation targeting rule.

\subsection{Alternative mechanisms for monetary injections}

The results up to this point rely on lump-sump taxes/transfers as the mechanism for conducting monetary policy. Below, we discuss two alternative mechanisms.

One alternative would be to inject money through open market operations.In our environment, government bonds will serve simply as an extra store of value and are directly held by the banks on behalf of their depositors. Schreft and Smith (2004) study the welfare role of government bonds in an economy similar to ours except that the rate of return on storage in their setup is stochastic. Since the return on

should be implemented. Similarly, under liquidity shocks,

$$
\pi_{t}=\frac{m_{t-1}}{m_{t}} \mu_{t}=\frac{m_{t-1}}{\alpha_{t-1}} \frac{\alpha_{t}}{m_{t}}=\frac{w+\tau_{t-1}}{w+\tau_{t}}=\frac{\alpha_{t-1}+1-\alpha_{t}}{\alpha_{t-2}+1-\alpha_{t-1}} .
$$

should be followed. 
these bonds are received only after the movers have left, in equilibrium non-movers consume stored goods as well as goods purchased from the cash returns on bonds. In sum, if bonds exist, non-movers consume stored goods as well as a part of the current endowment. Bhattacharya and Singh (2007) show that introducing government bonds does not improve welfare relative to the case where controlling money supply is the only policy option and money is injected in a lump-sum manner. This result can be easily extended to the environment of this paper.

An interesting alternative however is to consider money injections (withdrawals) through ad valorem transfers (taxes). Since money is held only by the old movers they are the sole recipients (payers) of such transfers (taxes). Formally, let the transfers be implemented in the following manner:

$$
M_{t+1}=\mu_{t} M_{t}
$$

where $\left(\mu_{t}-1\right)$ denotes the ad valorem transfer rate. It then directly follows that

$$
m_{t+1}=R_{m, t} \mu_{t} m_{t}
$$

Since the transfers only go to the old movers, the deposits by the young at the bank always equal the endowment. Therefore, period $t$ cash reserves of banks is $m_{t} \equiv \gamma_{t} w_{t}$. Note further that the movers of generation $t$ will have $m_{t+1}$ real balances net of transfers available for consumption in $t+1$. Thus, $c_{m, t}=\frac{m_{t+1}}{\alpha_{t}}=\frac{R_{m, t} \mu_{t} m_{t}}{\alpha_{t}}=$ $\frac{\gamma_{t} w_{t} R_{m, t} \mu_{t+1}}{\alpha_{t}}$. Accordingly, we rewrite the problem faced by the banks as

$$
\max _{\gamma_{t} \in[0,1]}\left\{\alpha_{t} E_{t}\left(u\left(\frac{\gamma_{t} w_{t} R_{m, t} \mu_{t+1}}{\alpha_{t}}\right)\right)+\left(1-\alpha_{t}\right) u\left(\frac{1-\gamma_{t}}{1-\alpha_{t}} w_{t} x\right)\right\} .
$$

With CRRA preferences, the first order condition for $\gamma_{t}$ is

$$
\gamma_{t}=\frac{\alpha_{t}}{\alpha_{t}+\left(1-\alpha_{t}\right) x^{\frac{1-\phi}{\phi}}\left[E_{t}\left\{\left(\frac{\gamma_{t+1} w_{t+1}}{\gamma_{t} w_{t}}\right)^{1-\phi}\right\}\right]^{-\frac{1}{\phi}}}
$$

which utilizes (48) and the identity $m_{t} \equiv \gamma_{t} w_{t}$. Clearly, $\gamma_{t}$ is independent of the transfer $\left(\mu_{t}\right)$ policy. Further, as $c_{m, t}=\frac{m_{t+1}}{\alpha_{t}}=\frac{\gamma_{t+1} w_{t+1}}{\alpha_{t}}$, the welfare is also independent of transfer policy. Thus, ad valorem rates are entirely irrelevant for welfare.

Intuitively, the consumption of movers is determined by the next period's banks' choice of fractional reserves, which in turn depends on the next-to-the-next period's 
choice and so on. In a rational expectations equilibrium, the bank chooses $\gamma$ to equate the marginal consumption of its non-movers (which is independent of nominal variables in any case) to that of its movers; but the latter is essentially determined by next period's banks. The rate of return on money is irrelevant.

Denote $\tilde{W}^{\text {prop }}$ as ex-ante welfare under ad valorem transfers. Then, for $u=\ln$, using (50) in (49) yields

$$
\tilde{W}^{\text {prop }}=\left\{\begin{array}{c}
E\{\ln w\}+(1-\alpha) \ln x, \text { for } \alpha_{t}=\alpha \forall t \\
\alpha^{e} E\{\ln \alpha\}-E\{\alpha \ln \alpha\}+\ln w+\left(1-\alpha^{e}\right) \ln x, \text { for } w_{t}=w \forall t
\end{array}\right.
$$

Under both types of shocks, the welfare equals that under a fixed money supply (see (22) and (35)). The transfers are irrelevant.

Thus, ad valorem transfers, state-contingent rule, and fixed money supply are all ex-ante equivalent under endowment shocks. However, as we already know, the welfare under optimal inflation targeting exceeds the welfare obtained under optimal monetary targeting $(\tilde{\mu}<1)$ which in turn dominates a fixed money supply rule $(\tilde{\mu}=1)$. Hence, ex-ante, ad valorem transfers are dominated by inflation targeting with lump-sum transfers.

\section{Conclusion}

This paper revisits the classic issue of the optimal choice of monetary instruments faced by central bankers around the world. To that end, we produce a two-period lived pure-exchange overlapping generations model in the tradition of Townsend (1987) and Champ, Smith, and Williamson (1997) where limited communication and stochastic relocation create an endogenous transactions role for fiat money. We study two kinds of shocks, real shocks (to the endowment) and liquidity shocks (to the fraction of agents relocating). First, our results indicate that when the shocks are real, welfare is higher under money growth targeting; when the shocks are nominal and not large, welfare is higher under inflation targeting. Secondly, while under inflation targeting it is always optimal to pursue an expansionary policy, it is never optimal to do so under money growth targeting.

We also examined alternative mechanisms for conduct of monetary policy. We find that there is no role for targeting rules when monetary injections are implemented 
through proportional money transfers. The equilibrium under proportional transfers can be obtained by a fixed money supply; the transfers are irrelevant. Similarly, conduct of open market operations would also have no welfare effects.

The models used in this paper do not include productive capital. It is safe to conjecture that adding capital would have strong implications for many of the results primarily because a propagation mechanism for shocks would then appear. Similarly, one could explore the likely impact on our results of assuming serially correlated shocks. There again, one can hazard a safe guess that for low levels of shock persistence, the results in the current paper would most likely continue to hold. In any case, these appear to be interesting avenues for future work. 


\section{References}

[1] Antinolfi, Gaetano, and Todd Keister "Discount Window Policy, Banking Crises, and Indeterminacy of Equilibrium", Macroeconomic Dynamics, 10, 1-19 (2006)

[2] Antinolfi, Gaetano, Elizabeth Huybens, and Todd Keister "Monetary Stability and Liquidity Crises: The Role of the Lender of Last Resort", Journal of Economic Theory, 99, 187-219 (2001)

[3] Bhattacharya, Joydeep, Haslag, J, and Steven Russell "The Role of Money in Two Alternative Models: When, and Why is the Friedman Rule Optimal", Journal of Monetary Economics, 52 (8), 1401-1433. (2005)

[4] Bhattacharya, Joydeep and Rajesh Singh "On the Usefulness of the Constrained Planning Problem in a Model of Money", ISU Working Paper \# 06027. (2007)

[5] Champ, Bruce, Bruce D. Smith and Stephen D. Williamson "Currency Elasticity and Banking Panics: Theory and Evidence", Canadian Journal of Economics, 29(4), 828-64 (1996)

[6] Diamond, Douglas and Philip Dybvig "Bank Runs, Deposit Insurance and Liquidity", Journal of Political Economy 85, 191-206 (1983)

[7] Gomis-Porqueras, Pere and Bruce D. Smith. "Seasonality and Monetary Policy", Macroeconomic Dynamics, 7(4), 477-502 (2003)

[8] Haslag, Joseph, and Antoine Martin "Optimality of the Friedman Rule in Overlapping Generations Models with Spatial Separation", forthcoming, Journal of Money, Credit, and Banking

[9] Paal, Beatrix and and Bruce D. Smith "The sub-optimality of the Friedman rule and the optimum quantity of money," manuscript UT-Austin (2004)

[10] Poole, W., "Optimal Choice of Monetary Policy Instruments in a Simple Stochastic Macromodel", Quarterly Journal of Economics, 84, 197-216 (1970)

[11] Schreft, Stacey and Bruce D. Smith. "Money, Banking, and Capital Formation", Journal of Economic Theory, 73, 157-82 (1997)

[12] — "The Social Value of Risk-free Government Debt", Federal Reserve Bank of Kansas City Working Paper \# 0302. (2004)

[13] Smith, Bruce D. "Efficiency and Determinacy of Equilibrium Under Inflation Targeting", Economic Theory, 4(3) 327-344 (1994)

[14] - "Monetary policy, Banking Crises, and the Friedman rule", American Economic Review, 92, 128-34 (2002)

[15] Stern, Gary, and Preston, Miller. "Avoiding Significant Monetary Policy Mistakes", Quarterly Review, Federal Reserve Bank of Minneapolis. (2004) 
[16] Townsend, Robert M. "Economic organization with limited communication," American Economic Review 77, 954-971 (1987)

[17] Wallace, Neil. "The Overlapping Generations Model of Fiat Money," in Models of Monetary Economies (J. Kareken and N. Wallace, eds.), 49-82, Minneapolis: Federal Reserve Bank of Minneapolis. (1980)

[18] Woodford, Michael Interest and Prices: Foundations of a Theory of Monetary Policy, Princeton University Press (2003) 


\section{Appendix}

\section{A Proof of Condition 1}

Suppose after reserving a fraction $\gamma$ of deposits for movers, banks may further split the rest $(1-\gamma)$ into money (a fraction $1-\theta$ ) and storage $(\theta)$ for non-movers. Then, the problem for the bank is

$\max _{\left\{\gamma_{t} \in[0,1], \theta_{t} \in[0,1]\right\}} E_{t}\left\{\alpha u\left(\frac{\gamma_{t}}{\alpha} R_{m, t}\left(w_{t}+\tau_{t}\right)\right)+(1-\alpha) u\left(\frac{\left(1-\gamma_{t}\right)\left(\theta_{t} x+\left(1-\theta_{t}\right) R_{m, t}\right)}{(1-\alpha)}\left(w_{t}+\tau_{t}\right)\right)\right\}$.

Define $c_{n, t} \equiv \frac{\left(1-\gamma_{t}\right)\left(\theta_{t} x+\left(1-\theta_{t}\right) R_{m, t}\right)}{(1-\alpha)}\left(w_{t}+\tau_{t}\right)$. The first order condition with respect to $\theta_{t}$ can be compactly written as

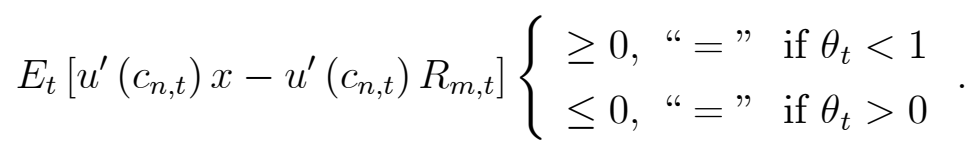

Note that when $\theta=1, c_{n, t}$ is non-stochastic, and the above condition reduces to

$$
x>E_{t}\left\{R_{m, t}\right\}
$$

With logarithmic utility, we know from (19) that $\frac{p_{t}}{p_{t+1}}=\frac{w_{t+1}}{\mu w_{t}}$. Then $x>E_{t}\left\{R_{m, t}\right\}$ will hold for all possible realizations of $w_{t}$ if and only if the condition in the statement of Condition 1 holds.

\section{B Proof of Proposition 3}

Using (27),

$$
W^{\pi}=-\alpha \ln \pi-\ln \alpha+(1-\alpha) \ln x+E(\ln m(\pi)),
$$

where the distribution of $m$ is governed by (25). We first take a second-order Taylor approximation of the last term around $m^{e}$ :

$$
E\{\ln m\} \simeq \ln m^{e}-\frac{1}{2} \frac{\sigma_{m}^{2}}{\left(m^{e}\right)^{2}}
$$

Using (26) with (52) in (51), and differentiating with respect to $\pi$ yields

$$
\frac{d W^{\pi}}{d \pi}=-\frac{\alpha}{\pi}+\frac{\frac{\alpha}{\pi^{2}}}{1-\alpha+\frac{\alpha}{\pi}}+\frac{1}{2} \frac{\sigma_{w}^{2}}{\left(w^{e}\right)^{2}} \frac{\alpha(1-\alpha)}{[(1-\alpha) \pi-\alpha]^{2}}
$$

Thus,

$$
\left.\frac{d W^{\pi}}{d \pi}\right|_{\pi=1}=\frac{1}{2} \frac{\sigma_{w}^{2}}{\left(w^{e}\right)^{2}} \frac{\alpha(1-\alpha)}{(1-2 \alpha)^{2}}>0
$$

Assuming $W^{\pi}$ is concave in $\pi$, the above implies $\tilde{\pi}>1$ 


\section{Proof of Condition 2}

The proof follows that of Condition 1 closely. To begin with, note that $\alpha_{t}$ is known at the start of $t$. Then, as in the proof of Condition 1, the required condition reduces to $x>E_{t}\left\{R_{m, t}\right\}$. Using (32), it follows that

$$
\begin{aligned}
& x>E_{t}\left\{R_{m, t}\right\} \Leftrightarrow \\
& x>E_{t}\left\{\frac{\alpha_{t+1}}{\underline{\alpha}} \frac{1-\underline{\alpha}\left(1-\frac{1}{\mu}\right)}{\mu\left[1-\alpha_{t+1}\left(1-\frac{1}{\mu}\right)\right]}\right\} \Leftrightarrow \\
& x>\frac{1}{\mu} E\left\{\frac{\alpha}{\underline{\alpha}} \frac{\mu-\underline{\alpha}(\mu-1)}{\mu-\alpha(\mu-1)}\right\} .
\end{aligned}
$$

\section{Proof of Proposition 4}

We start by computing the maximized value of stationary welfare under monetary targeting, denoted by $\tilde{W}^{\mu}$. From (22), it can be checked that at $\mu=1$,

$$
\tilde{W}^{\mu}=(1-\alpha) \ln x+\int_{\underline{w}}^{\bar{w}}\{\ln w\} f(w) d w .
$$

Analogous to (52), we can write $\int_{\underline{w}}^{\bar{w}}\{\ln w\} f(w) d w \equiv E\{\ln w\} \simeq \ln w^{e}-\frac{1}{2} \frac{\sigma_{w}^{2}}{\left(w^{e}\right)^{2}}$ and SO

$$
\tilde{W}^{\mu}=(1-\alpha) \ln x+\ln w^{e}-\frac{1}{2} \frac{\sigma_{w}^{2}}{\left(w^{e}\right)^{2}}
$$

Denote by $W^{\pi}$, the maximized value of stationary welfare under inflation targeting. From (28), it follows that

$$
\tilde{W}^{\pi}=-\alpha \ln \tilde{\pi}-\ln \alpha+(1-\alpha) \ln x+E(\ln m(\tilde{\pi})),
$$

where it is known from Proposition 3 that $\tilde{\pi}>1$. Using (52) and (26), note that

$$
E\{\ln m(\tilde{\pi})\}=\ln m^{e}-\frac{1}{2} \frac{\sigma_{m}^{2}}{\left(m^{e}\right)^{2}}=\ln \frac{\alpha w^{e}}{1-\alpha+\frac{\alpha}{\tilde{\pi}}}-\frac{1}{2} \frac{\sigma_{w}^{2}}{\left(w^{e}\right)^{2}} \frac{(1-\alpha) \tilde{\pi}+\alpha}{(1-\alpha) \tilde{\pi}-\alpha} .
$$

Then

$$
\tilde{W}^{\pi}=-\alpha \ln \tilde{\pi}-\ln \alpha+(1-\alpha) \ln x+\ln w^{e}-\ln \left(\frac{1-\alpha}{\alpha}+\frac{1}{\tilde{\pi}}\right)-\frac{1}{2} \frac{\sigma_{w}^{2}}{\left(w^{e}\right)^{2}} \frac{(1-\alpha) \tilde{\pi}+\alpha}{(1-\alpha) \tilde{\pi}-\alpha}
$$


Then it is easily checked that

$$
\tilde{W}^{\mu}-\tilde{W}^{\pi}=\alpha \ln \tilde{\pi}+\ln \left(1-\alpha+\frac{\alpha}{\tilde{\pi}}\right)+\frac{\sigma_{w}^{2}}{2\left(w^{e}\right)^{2}} \frac{\alpha}{(1-\alpha) \tilde{\pi}-\alpha}
$$

The third term on the r.h.s of (53) is positive by virtue of assumption (??). How about the first two terms? The first one is positive as and the second one is negative as it is known that $\tilde{\pi}>1$. Notice that the first term increases with $\tilde{\pi}$ while the second one decreases. What is the minimum of the sum of the first two terms in terms of $\tilde{\pi}$ ? If we can show that the sum reaches a minimum at $\tilde{\pi}=1$ and is nonpositive, then we would know that the sum is positive for $\tilde{\pi}>1$. Differentiating $\alpha \ln \tilde{\pi}+\ln \left(1-\alpha+\frac{\alpha}{\tilde{\pi}}\right)$ with respect to $\tilde{\pi}$ yields a turning point of $\tilde{\pi}=1$ and $\tilde{\pi}=\infty$. Checking the second derivative reveals that the sign is positive at $\tilde{\pi}=1$ implying that $\alpha \ln \tilde{\pi}+\ln \left(1-\alpha+\frac{\alpha}{\tilde{\pi}}\right)$ is a global minimum at $\tilde{\pi}=1$ and so the minimum value of $\alpha \ln \tilde{\pi}+\ln \left(1-\alpha+\frac{\alpha}{\tilde{\pi}}\right)=0$; clearly since $\tilde{\pi}>1, \alpha \ln \tilde{\pi}+\ln \left(1-\alpha+\frac{\alpha}{\tilde{\pi}}\right)>0$ holds.

\section{E Proof of Proposition 5}

Differentiating the ex-ante welfare expression in (35) with respect to $\mu$ yields

$$
\frac{d}{d \mu} W^{\mu}=-\frac{\alpha^{e}}{\mu}+\frac{1}{\mu^{2}} \int_{\underline{\alpha}}^{\bar{\alpha}} \frac{1-\left(\alpha-\alpha^{e}\right)}{1-\alpha\left(1-\frac{1}{\tilde{\mu}}\right)} \alpha g(\alpha) d \alpha .
$$

Evaluating the above expression at $\mu=1$ obtains

$$
\begin{aligned}
& \left.\frac{d}{d \mu} W^{\mu}\right|_{\mu=1}=\alpha^{e}\left(-1+\frac{1}{\alpha^{e}} \int_{\underline{\alpha}}^{\bar{\alpha}}\left[\alpha-\alpha\left(\alpha-\alpha^{e}\right)\right] g(\alpha) d \alpha\right) \\
& =.-\int_{\underline{\alpha}}^{\bar{\alpha}} \alpha\left(\alpha-\alpha^{e}\right) g(\alpha) d \alpha=-\left[\int_{\underline{\alpha}}^{\bar{\alpha}} \alpha^{2} g(\alpha) d \alpha-\alpha^{e} \int_{\underline{\alpha}}^{\bar{\alpha}} \alpha g(\alpha) d \alpha\right] \\
& =-\left[E\left(\alpha^{2}\right)-(E(\alpha))^{2}\right] \equiv-\sigma_{\alpha}^{2}<0
\end{aligned}
$$

Since $W^{\mu}$ is assumed to be concave in $\mu$, the above implies that $\tilde{\mu}<1$.

\section{F Proof of Proposition 6}

Define $\frac{\alpha_{t}}{1-\alpha_{t}} \equiv \rho_{t}$. Then $\rho^{e} \equiv E\{\rho\}$ and $\sigma_{\rho}^{2} \equiv E\left\{\left(\rho-\rho^{e}\right)^{2}\right\}$. Then

$$
m_{t}=-\frac{\alpha_{t}}{\left(1-\alpha_{t}\right) \pi} m_{t-1}+\frac{\alpha_{t}}{1-\alpha_{t}} w_{t} \Leftrightarrow m_{t}=\rho_{t}\left(w-\frac{1}{\pi} m_{t-1}\right)
$$


Taking expectations on both sides, we get

$$
m^{e}=\rho^{e}\left(w-\frac{1}{\pi} m^{e}\right), \text { or } m^{e}=\frac{\rho^{e}}{1+\frac{\rho^{e}}{\pi}} w
$$

Squaring both sides of (54) and taking expectations yields

$$
\sigma_{m}^{2}+\left(m^{e}\right)^{2}=E\left(\rho^{2}\right)\left[\frac{1}{\pi^{2}} \sigma_{m}^{2}+\left(w-\frac{1}{\pi} m^{e}\right)^{2}\right]
$$

which using the preceding equation can be rewritten as

$$
\frac{\sigma_{m}^{2}}{\left(m^{e}\right)^{2}}=\frac{\sigma_{\rho}^{2}}{1-\frac{E\left(\rho^{2}\right)}{\pi^{2}}}
$$

Using (26) with (52) in (51), differentiating (51) with respect to $\pi$ yields

$$
\frac{d W^{\pi}}{d \pi}=-\frac{\alpha^{e}}{\pi}+\frac{\frac{\rho^{e}}{\pi^{2}}}{1+\frac{\rho^{e}}{\pi}}+\frac{1}{2} \frac{\sigma_{\rho}^{2} \frac{E\left(\rho^{2}\right)}{\pi^{3}}}{\left(1-\frac{E\left(\rho^{2}\right)}{\pi^{2}}\right)^{2}} .
$$

It follows that

$$
\left.\frac{d W^{\pi}}{d \pi}\right|_{\pi=1}=-\alpha^{e}+\frac{\rho^{e}}{1+\rho^{e}}+\frac{1}{2} \frac{\sigma_{\rho}^{2} E\left(\rho^{2}\right)}{\left(1-E\left(\rho^{2}\right)\right)^{2}}
$$

Note that $\rho_{E}=E\left\{\frac{\alpha}{1-\alpha}\right\}=E\left\{\frac{1}{1-\alpha}-1\right\}>\frac{1}{E\{1-\alpha\}}-1=\frac{\alpha^{e}}{1-\alpha^{e}}$. Hence, $\frac{1}{\alpha^{e}}-1>\frac{1}{\rho^{e}}$ or $\frac{\rho^{e}}{1+\rho^{e}}>\alpha^{e}$. Thus,

$$
\left.\frac{d W^{\pi}}{d \pi}\right|_{\pi=1}>\frac{1}{2} \frac{\sigma_{\rho}^{2} E\left(\rho^{2}\right)}{\left(1-E\left(\rho^{2}\right)\right)^{2}}>0
$$

Assuming $W^{\pi}$ is concave in $\pi$, the above implies that $\tilde{\pi}>1$.

\section{G "Proof" of Claim 1}

We know that under certainty $\tilde{W}^{\pi}=\tilde{W}^{\mu}$. Below, we show that introducing an infinitesimal amount of uncertainty makes one regime dominate the other depending on the value of $\alpha$ in the deterministic case. The result has been verified numerically for all levels of uncertainty. Recall

$$
\begin{aligned}
& W^{\pi}=-\alpha^{e} \ln \pi+\left(1-\alpha^{e}\right) \ln x+E\{\ln (w+\tau(\pi))\} \\
& W^{\mu}=\left(1-\alpha^{e}\right) \ln x+\ln w-\alpha^{e} \ln \mu-E\left\{\left(\alpha-\alpha^{e}\right) \ln \alpha\right\}-E\left\{\left(1-\left(\alpha-\alpha^{e}\right)\right) \ln \left[1-\alpha\left(1-\frac{1}{\mu}\right)\right]\right\}
\end{aligned}
$$


Then

$$
\begin{aligned}
W^{\pi}-W^{\mu}= & -\alpha^{e} \ln \frac{\pi}{\mu}+E\{\ln (w+\tau(\pi))\}-\ln w+E\left\{\left(\alpha-\alpha^{e}\right) \ln \alpha\right\} \\
& +E\left\{\left(1-\left(\alpha-\alpha^{e}\right)\right) \ln \left[1-\alpha\left(1-\frac{1}{\mu}\right)\right]\right\}
\end{aligned}
$$

Note that for small amount of uncertainty, using Taylor expansion, we can get

$$
E\left\{\left(\alpha-\alpha^{e}\right) \ln \alpha\right\} \simeq E\left(\frac{\left(\alpha-\alpha^{e}\right)^{2}}{\alpha^{e}}\right)=\frac{\sigma_{\alpha}^{2}}{\alpha^{e}}
$$

where the inequality follows from the assumption of a symmetric distribution for $\alpha$. Similarly,

$$
E\{\ln (w+\tau(\pi))\} \simeq \ln (E\{w+\tau(\pi)\})-\frac{1}{2} \frac{\sigma_{w+\tau}^{2}}{(E\{w+\tau\})^{2}}
$$

For future use, let's first compute the mean and the variance of $w+\tau(\pi)=\frac{m(\pi)}{\alpha}$ under inflation targeting. Recall that $m$ 's distribution is governed by:

$$
m_{t}=-\frac{\rho_{t}}{\pi} m_{t-1}+\rho_{t} w
$$

where $\rho \equiv \frac{\alpha}{1-\alpha}$. It has been shown that

$$
\begin{aligned}
m^{e} & =\frac{\rho^{e}}{1+\frac{\rho^{e}}{\pi}} w \\
\sigma_{m}^{2} & =\frac{\sigma_{\rho}^{2}}{1-\frac{E\left(\rho^{2}\right)}{\pi^{2}}}\left(\frac{1}{1+\frac{\rho^{e}}{\pi}}\right)^{2} w^{2}
\end{aligned}
$$

Note that (58) can be written as

$$
\frac{m_{t}}{\alpha_{t}}=w+\tau_{t}=w+m_{t}-\frac{m_{t-1}}{\pi}
$$

Then,

$$
\begin{aligned}
E\{w+\tau\} & =E\left\{\frac{m}{\alpha}\right\}=w+\left(1-\frac{1}{\pi}\right) m^{e} \\
& =\frac{1+\rho^{e}}{1+\frac{\rho^{e}}{\pi}} w
\end{aligned}
$$

Further, after some algebra, it can be shown that

$$
\operatorname{Var}\{w+\tau(\pi)\}=\left(1+\frac{1+2 \rho^{e}}{\pi^{2}}\right) \frac{\sigma_{\rho}^{2}}{1-\frac{E\left(\rho^{2}\right)}{\pi^{2}}}\left(\frac{1}{1+\frac{\rho^{e}}{\pi}}\right)^{2} w^{2}
$$


We want to show that introducing an infinitesimal amount of uncertainty makes one regime superior to another. Notice that when both $w$ and $\alpha$ are deterministic, $\tilde{\mu}=\tilde{\pi}=1$. Our idea is to use Envelope theorem to see if introducing an infinitesimal uncertainty (around certainty) makes $W^{\pi}-W^{\mu} \neq 0$. Can we sign the welfare difference at the margin then? To fix ideas, consider the following experiment. Suppose $\alpha$ is stochastic, uniform and i.i.d. over support $\left[\alpha^{e}-\epsilon, \alpha^{e}+\epsilon\right]$, and assume that $\frac{\alpha^{e}+\epsilon}{1-\left(\alpha^{e}+\epsilon\right)}<1$. If $\epsilon=0$, then obviously

$$
\tilde{W}^{\pi}-\tilde{W}^{\mu}=0
$$

We want to evaluate

$$
\left.\frac{d}{d \epsilon}\left(\tilde{W}^{\pi}-\tilde{W}^{\mu}\right)\right|_{\epsilon=0}
$$

Invoking Envelope theorem implies that we only need to evaluate

$$
\left.\frac{d}{d \epsilon}\left(W^{\pi=1}-W^{\mu=1}\right)\right|_{\epsilon=0}
$$

to sign $(61)$.

Thus, substituting $\pi=\mu=1$ in (55) yields

$$
W^{\pi=1}-W^{\mu=1}=E\{\ln (w+\tau(\pi))\}-\ln w+E\left\{\left(\alpha-\alpha^{e}\right) \ln \alpha\right\}
$$

For any distribution, fix $\frac{\sigma_{\alpha}}{\alpha^{e}}=\delta$, where $\delta$ can be made arbitrarily small. Then, we can use Taylor series approximation (56) and (57) in (62) as higher order terms can be readily neglected. Substituting $\pi=1$ in (59) and (60), and using (56) and (57) in (62), we get

$$
\begin{aligned}
W^{\pi=1}-\left.W^{\mu=1}\right|_{\frac{\sigma_{\alpha}}{\alpha^{e}}=\delta} & =\frac{\sigma_{\alpha}^{2}}{\alpha^{e}}-\frac{\sigma_{\rho}^{2}}{1-E\left(\rho^{2}\right)} \frac{1}{1+\rho^{e}} \\
& =\alpha^{e} \delta^{2}-\frac{\frac{\sigma_{\chi}^{2}}{\left(\chi^{e}\right)^{2}}}{1-\rho^{e}-\frac{\sigma_{\chi}^{2}}{\left(\chi^{e}\right)^{2}}}
\end{aligned}
$$

where $\chi \equiv \frac{1}{1-\alpha}$. It is easy to verify that $\frac{\sigma_{\chi}^{2}}{\chi^{2}}<<\delta^{2}$ for small values of $\alpha^{e}$. On the other hand, as $\alpha^{e}$ increases $\rho^{e}$ increases and the denominator in the second term gets smaller. Thus, by continuity, there exists an $\hat{\alpha}$ for each $\delta$ such that $W^{\pi=1}-\left.W^{\mu=1}\right|_{\frac{\sigma_{\alpha}}{\alpha^{e}}=\delta} \gtrless 0$ for all $\alpha^{e} \lessgtr \hat{\alpha}$.

\section{H Proof of Proposition 7}

Since $\alpha_{t}-\alpha_{t-1}$ or $\alpha_{t+1}-\alpha_{t}$ is small, we have

$$
\begin{aligned}
& \alpha_{t} \ln \left(1-\alpha_{t+1}+\alpha_{t}\right) \simeq \alpha_{t}\left(\alpha_{t}-\alpha_{t+1}\right), \\
& \alpha_{t} \ln \left(1-\alpha_{t}+\alpha_{t-1}\right) \simeq \alpha_{t}\left(\alpha_{t-1}-\alpha_{t}\right) .
\end{aligned}
$$


Then, to a second order approximation:

$$
E\left(-\alpha_{t} \ln \left(1-\alpha_{t+1}+\alpha_{t}\right)+\alpha_{t} \ln \left(1-\alpha_{t}+\alpha_{t-1}\right)\right) \simeq 0 .
$$

Also to a second order approximation

$$
\ln \left(1-\alpha_{t}+\alpha_{t-1}\right) \simeq \sigma_{\alpha}^{2}
$$

This gets

$$
\begin{aligned}
E\left\{\tilde{W}_{t}^{s c}\right\} & \simeq \ln w+\left(1-\alpha^{e}\right) \ln x+\sigma_{\alpha}^{2} \\
& >\ln w+\left(1-\alpha^{e}\right) \ln x+\sigma_{\alpha}^{2}
\end{aligned}
$$

Recall that the welfare under optimal inflation targeting $-\alpha^{e} \ln \pi+\left(1-\alpha^{e}\right) \ln x+$ $E\{\ln (w+\tau(\pi))\}<\ln w+\left(1-\alpha^{e}\right) \ln x$. This is because with no liquidity shocks, $\tilde{\pi}=1$ and the welfare equals the r.h.s. of the inequality; under shocks the welfare is lower. Thus, as one would expect, state-contingent rules strictly dominate inflation targeting under liquidity shocks. 
Iowa State University does not discriminate on the basis of race, color, age, religion, national origin, sexual orientation, gender identity, sex, marital status, disability, or status as a U.S. veteran. Inquiries can be directed to the Director of Equal Opportunity and Diversity, 3680 Beardshear Hall, (515) 294 - 7612 . 